\title{
EFFECT OF SURFACTANT ADDITION ON THE NANOFLUIDS PROPERTIES: A REVIEW
}

\author{
Kadhum Audaa Jehhef* and Mohamed Abed Al Abas Siba \\ Department of Machines and Equipment, Institute of Technology, Middle Technical University, Iraq \\ *Corresponding Author Email: kadhum.audaa@yahoo.com
}

This is an open access article distributed under the Creative Commons Attribution License, which permits unrestricted use, distribution, and reproduction in any medium, provided the original work is properly cited.

\section{ARTICLE DETAILS}

\section{Article History:}

Received 01 May 2019

Accepted 11 June 2019

Available online 17 June 2019

\section{ABSTRACT}

The applications and usage of surfactants in the field of nanofluids heat transfer and its stability were performed the present literature review. The usage of surfactants has been employed for the following areas of nanofluids study: nanofluid heat transfer, nanofluid agglomeration and nanofluid enhancement stability. Generally, a few interesting has been achieved to study the effects of using the surfactants on the nanofluids properties such as $\mathrm{pH}$, thermal conductivity, specific heat, electrical conductivity, viscosity and stability mechanism of nanofluid. The using nanofluid in real applications is taken into consideration by two key issues emerge: erosion and settlement but there aare possible difficulties related to these issues that need to be studied and solved prior to the using of nanofluid in commercial applications. In addition, this paper summarizes the theoretical and experimental studies on the effects of applied various types of surfactants in nanofluids. This work can serve as a ready reference for application of surfactants in nanofluids.

\section{KEYWORDS}

Surfactant Additives, Nanofluids Stability, Nanofluids Agglomeration, Surface Tension

\begin{abstract}
1. INTRODUCTION
The concept of nanofluid was proposed by a researcher in 1995 [1]. Nanofluid shows a promising future as heat transfer fluids due to its better stability increase in thermal conductivity. The advantages of nanofluid utilization include (i) higher thermal conductivities; (ii) excellent stability; and (iii) negligible penalty in pumping power due to pressure drop and pipe wall abrasion. The Nanofluids can be defined as a nanometric colloidal mixture that dispersed in a base fluid such as water, ethylene glycol or oil to obtain the heat transfer enhancement character of the base fluid caused by the enhanced the thermo-physical properties of the base fluid such as thermal conductivity, specific heat, density and viscosity. Nanofluids used as a heat-carrying liquids that have conductivities 10$40 \%$ higher than those of the base fluid and hence a greatly enhanced heat transfer efficiency [2].
\end{abstract}

Nanofluid is described as a fluids of heat transfer which produced by dispersing nanoparticles in base fluis heat transfer along with a surfactant to increase their thermal stability. Nanofluid show better stability, high thermal conductivity with negligible pressure drop as compared with suspended conventional particles of milli or micro meter dimensions. Nanofluid can be used in various thermal cooling systems such as engines/vehicles, chillers, heat pipes, electronics cooling, solar water heating systems, cooling of nuclear systems, refrigeration systems [3]. Additives such as stabilization agent or surfactant are usually are used to modify the solid/liquid interface or to prevent the aggregation of nanoparticles. However, the common additives are usually disabled when the temperature of nanofluids is high. It is necessary to synthesize special additives according to the nanofluids system for the aim of nanofluids commercial application.

To achieved the stabilization of the nanofluids, surfactants are generally used. The surfactants addition will lead to increase the immersion of particles and lowers the surface tension of base fluids. A few literatures talk about adding surfactant to nanoparticles to avoid fast sedimentation however, enough surfactant should be added to particle at any particular case. Thus, in this paper, a simple brief review has been carried out to study the features of using surfactants, such as surfactants types, surfactants effects on nanofluids thermal stabilizers and surfactants effect on the nanofluids properties such as density, viscosity, specific heat thermal conductivity, $\mathrm{pH}$, zeta potentials and electrical conductivity. Also, this paper is discussed the surfactants effects on the heat transfer enhancement by nanofluid, etc.

The major important of this study, it gives a rapped review for the effect of the surfactants on the properties of the nanofluid, and the reader can make a decision the chose the type of surfactant.

\section{SURFACTANTS}

Vast variety of additives such as dispersants and surfactants have been applied in nanofluids which consist of salts, organic acids and polymer surfactants. These dispersants include certain surfactants and hydrophilic polymers. This mechanism can be used by stabilized system in order to remain good nanoparticles dispersed in the base fluids loading or under normal conditions, also, to obtain near zero of the zeta potentials of the surfaces. A numerous study has used this method of stabilization in producing stabilized nanofluids. A researcher used polyacrylamide (PAM) and polyethylene glycol (PEG) polymers to get satirically stabilization of $\mathrm{TiO}_{2}$ nanoparticles [4]. A researcher used the Gum Arabic (GA) to get longest stabilized nanofluid that containing CNT [5]. Also, the dispersing power of various surfactants to enhance the CNT nanofluids stabilization characteristics was investigated by a previous researcher [6]. In many researches, there are various types of surfactants had been used for different types of nanofluids, Table 1 presented several of them that were used by many researchers. 
Table 1: Summary of types of surfactant was used in various previous literatures.

\begin{tabular}{|c|c|}
\hline Types of Surfactant & Author Name \\
\hline $\begin{array}{l}\text { Poly-Vinyl-Pyrrolidone (PVP) } \\
\text { Gum Arabic (GA) } \\
\text { Hexadecyl-Trimethyl-Ammonium-bromide (CTAB) }\end{array}$ & [7] \\
\hline $\begin{array}{l}\text { Disponil A } 1580 \\
\text { Hydropalat } 5040 \\
\text { Antiterra } 250 \\
\text { Disperbyk } 190 \\
\text { Hypermer LP1 } \\
\text { Aerosol TR-70 } \\
\text { Aerosol TR-70 HG } \\
\text { Aerosol OT-70 PG } \\
\text { Gum Arabic }\end{array}$ & {$[8]$} \\
\hline $\begin{array}{l}\text { Oleic Acid } \\
\text { CTAB } \\
\text { Laurate salt } \\
\text { Sodium dodecyl sulfate (SDS) }\end{array}$ & [9] \\
\hline $\begin{array}{l}\text { Oleic acid } \\
\text { Cetyltrimethyammonium bromide (CTAB). }\end{array}$ & [3] \\
\hline $\begin{array}{l}\text { Anionic(SDS) } \\
\text { Cationic(CTAB) } \\
\text { Nonionic (LAE-7) } \\
\text { Amphoteric (CHAPS) }\end{array}$ & [10] \\
\hline nonionic surfactant & [11] \\
\hline $\begin{array}{l}\text { (Rokacet 07 RO }(\mathrm{CH} 2 \mathrm{CH} 2 \mathrm{O}) \mathrm{nH} \text { ethoxylated unsaturated fatty alcohols } \\
\text { Rokanol K7 RCOO }(\mathrm{CH} 2 \mathrm{CH} 2 \mathrm{O}) \mathrm{nH} \text { product of ethoxylation of oleic acid. }\end{array}$ & [12] \\
\hline $\begin{array}{l}\text { Anionic surfactants } \\
\text { Nonionic surfactants } \\
\text { Cationic surfactants } \\
\text { Amphoteric surfactants }\end{array}$ & [13] \\
\hline Sodium dodecyl benzene sulfonate. & [14] \\
\hline Cetyltrimethylammonium bromide (CTAB) & [15] \\
\hline Cetyl Trimethyl Ammonium Bromide (CTAB) & [16] \\
\hline $\begin{array}{l}\text { salt. } \\
\text { Oleic acid. }\end{array}$ & [17] \\
\hline $\begin{array}{l}\text { Oleic acid. } \\
\text { Cetyltrimethy lammoniumbromide (CTAB). }\end{array}$ & [18] \\
\hline Sodium Dodecyl Sulphate (SDS) 0.44-0.8 \%vol. & [19] \\
\hline $\begin{array}{l}\text { gum Arabic. } \\
\text { gemini. } \\
\text { sodium dodecylbenzene sulfonate (SDBS). }\end{array}$ & [20] \\
\hline Chitosan loading $0.1,0.2$ and 0.5 wt. $\%$ & [21] \\
\hline Sodium dodecyl benzene sulfonate (SDBS). & [22] \\
\hline Bile salt & [23] \\
\hline polyvinylpyrrolidone (PVP) & [24] \\
\hline oleic acid & {$[25]$} \\
\hline cationic Gemini & [26] \\
\hline Concentration of oleic acid & [27] \\
\hline CTAC(cetyltrimethylammoniumchloride) & [28] \\
\hline gum Arabic & [29] \\
\hline $\begin{array}{ll}\text { Nonionic surfactant Rokanol K7 (500ppm) } & \text { Cetyltrimethyl } \\
\text { Ammonium Bromide } & \\
\text { Sorbitan Monooleate (Span-80). } & \end{array}$ & [30] \\
\hline Ionic surfactant. (SDBS, Lignin, Sodium polycarboxylate) & [31] \\
\hline Oleic acid (1 vol. \%) & [32] \\
\hline surfactant composed of sulphuric and nitric acids & [33] \\
\hline
\end{tabular}


In order to enhance the stability of water-Cu and transformer oil- $\mathrm{Cu}$ nanofluids, respectively, a group of researchers were choosing oleic acid and salt as the dispersant [34]. Also, cetyltrimethylammonium bromide (CTAB) and surfactants of oleic acid were utilized by a scholar to obtain a proper dispersion and better stability of $\mathrm{TiO}_{2}-\mathrm{H}_{2} \mathrm{O}$ nanofluid [35]. (SDS) was utilized by a researcher during the preparation of MWCNT- $\mathrm{H}_{2} \mathrm{O}$ nanofluid [36]. Later, a researcher used similar measurements but with applying CDWNTs and CMWNTs with using CTAB [37].

Surfactants used in nanofluid also called dispersants that used to enhance the stability of nanofluids. Adding dispersants in two-phase nanofluid system is an easy and economic method. Dispersants consists of a hydrophobic tail portion, usually a long-chain hydrocarbon, and a hydrophilic polar head group Xie [38]. The using surfactants in the liquid of carrying can prevent the nanoparticles agglomeration. Fig.1 shows a pictorial representation of the surfactant molecule around the nanoparticle [39].

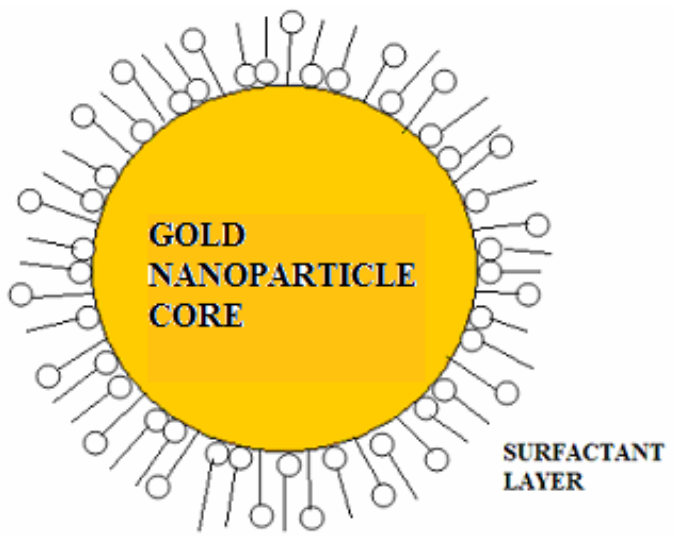

Figure 1: Surfactant layer of CTAB around the gold nanoparticles [39].

Surfactants referred to the chemical compound that adding to the nanofluids mixtures to improve the nanoparticles immersion and to decrease the surface tension of liquids. Numerous studies presented the effect of adding surfactant to nanofluid in order to prevent the fast sedimentation. But, this method dose not valid for high temperature nanofluid to avoid the damage of bonding between surfactant and nanoparticle [40].

Generally, surfactants are utilized in nanofluid as stabilizing agents and it affect interfacial characteristics the base fluid, to avoid the sedimentation of nanoparticles in the nanofluid [41].

The role of using the surfactants is to obtain an efficient and effective coating to induce steric or electrostatic repulsions to counterbalance the van der Waals attractions between the nanoparticles and base fluid. Thus, surfactants can be classified into three classes:

Surfactants of Nonionic

Surfactants of Anionic

Surfactants of Cationic

The solution stabilization by using ionic surfactants results from the electrostatic repulsion between the ionic hydrophilic heads. The anionic surfactants as SDBS as shown in Fig.2 are a series of organic compounds with the formula $\mathrm{C} 12 \mathrm{H} 25 \mathrm{C} 6 \mathrm{H} 4 \mathrm{SO} 3 \mathrm{Na}$. It is a colorless salt with useful properties as a surfactant [42]<smiles>CCCCCc1ccc(S(=O)(=O)O[Na])cc1</smiles>

Figure 2: Structure of SDBS surfactant [42].

And SDS surfactant with long-chain fatty acids; alkyl sulfate is shown in Figure 3

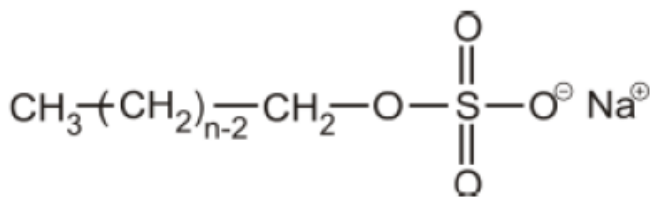

Figure 3: Structure of SDS surfactant [42].

Both SDBS and SDS are excellent for using in nanofluids electrostatic stabilizers with high affinity to absorb onto nanoparticle surfaces. In the absence of the surfactant and form highly ramified aggregates due to the lack of electrostatic repulsion, causes graphene sheets and van der Waals attraction dominate. In order to causes the aggregates of graphene sheets it should be grow repulsion from adsorbed surfactant, but when increasing the surfactant concentration to increase in sheet-sheet overlap area and then to develop a more compact structure.

Gum Arabic was used by a researcher, they prepared CMWNTs/water nanofluid. The samples were stable for months without any significant sedimentation [43]. A researcher produced a stable CMWNTs/water nanofluid by using gemini cationic surfactant of type trimethylene-1, 3-bis (dodecyldimethyl ammonium bromide) [44]. Based on a study, the effect of chitosan loading on the multiwalled carbon nanotube in water base fluid. They found that thermal conductivity enhancement ranging from 2.3 to $13 \%$ for nanofluid containing 0.5 to $3 \mathrm{wt}$. \% of CMWNTs/water. Moreover, a researcher employed SDBS surfactant and they found that the thermal conductivity enhancement was about $19.73 \%$ for $0.45 \%$ MWCNT/water/ethylene glycol volume fraction at $40{ }^{\circ} \mathrm{C}$ [45]. Also, the thermal conductivity of SWCNT/ethylene glycol with surfactant of bile salt was studied by a scholar [46].

\section{TYPES OF SURFACTANTS}

In process of preparation the nanoflids, there is various technique methods include ultrasonic equipment, $\mathrm{pH}$ control of nanofluid or adding of surface-active agents (surfactants) are utilized to reach the stability of the nanofluids suspension. These methods used to change the properties of nanoparticles surfaces to avoid nanoparticle clusters. In many researches, there are various types of surfactant had been utilized for different kinds of nanofluids. The details of some surfactants and its chemical are shown in Table 2 [47]. Some important surfactants are: GA, DTAB, PVP, HCTAB, NDDBS, Dextrin, SDS, NaDDBS, NaOBS, Long chain synthetic polymer (PEO), Salt and oleicacid, Negatively charged SDS, Positively charged CTAC, Sodium benzoate (CsHsCCNa), Triton X-100, Oleic acid, Sodium laurate salt, Hydrochloric acid

Table 2: A list of surfactants and dispersants and their manufacturers [47]

\begin{tabular}{|l|l|l|}
\hline $\begin{array}{l}\text { Surfactant/ } \\
\text { Dispersant }\end{array}$ & Chemical Formula & Description \\
\hline Gum Arabic & $\begin{array}{l}\text { Complex mixture of } \\
\text { arabinogalactan } \\
\text { oligosaccharides, } \\
\text { polysaccharides } \\
\text { glycoproteins }\end{array}$ & $\begin{array}{l}\text { Crystalline powder, } \\
\text { lightly beige in } \\
\text { color }\end{array}$ \\
\hline Oleic Acid & C17H33COOH & $\begin{array}{l}\text { Clear liquid, } \\
\text { colorless with fatty } \\
\text { odor }\end{array}$ \\
\hline $\begin{array}{l}\text { Sodium } \\
\text { Laurate } \\
\text { Salt }\end{array}$ & C12H23Na02 & $\begin{array}{l}\text { Solid, white in } \\
\text { color and odorless }\end{array}$ \\
\hline $\begin{array}{l}\text { Sodium } \\
\text { dodecyl } \\
\text { benzene } \\
\text { sulfonate } \\
\text { (NDDBS) }\end{array}$ & C12H25C6H4SO3 Na & $\begin{array}{l}\text { Crystalline powder, } \\
\text { white or light-yellow } \\
\text { flakes }\end{array}$ \\
\hline $\begin{array}{l}\text { Hydrochloric } \\
\text { acid }\end{array}$ & $\mathrm{HCl}$ & Colorless \\
\hline Nitric acid & $\mathrm{HNO3}$ & Colorless \\
\hline $\begin{array}{l}\text { Sodium } \\
\text { hydroxide }\end{array}$ & $\mathrm{NaOH}$ & Colorless \\
\hline
\end{tabular}




\section{NANOFLUIDS STABILITY AND AGGLOMERATION PHENOMENON}

The stability nanofluid has a major impact on the effective thermal conductivity of the fluid. Compared with millimetre or micrometre-sized particle suspensions, nanofluids possess better long-term rheological and stability properties, and can have dramatically increased thermal conductivities, but in industrial applications, there are some surfactant problems are also founded as poor stability, pipelines eroding, flow channels clogging and pressure drop increasing [48].

Nanoparticles is difficult to disperse in water and easy to coagulate because the high surface energy of nanoparticles, therefore, controlling coagulation of nanofluid has become the primary issue for the initial research of nanofluid [49]. This agglomeration of nanoparticles leads to generate the sedimentation and cause a non-homogenous dispersion of nanoparticles. Sedimentation phenomena affect the distribution of the particle concentration in the flow [50,51].

The phase separation between the nanoparticles and base fluid is induced by the gravitation and this led to sediment the nanoparticle in the rear of nanofluid container. Therefore, there is an interaction between suspension-driven sedimentation and the gravity. Thus, the stability of nanofluid can be damaged by the sedimentation phenomenon. There are several literatures studied the relationship between the nanofluids stability and nanofluid thermo-physical propertied especially the thermal conductivity. A researcher used cationic Gemini surfactant to stabilize the CNT [52]. Their results presented by zeta potential and showed that the nanofluid tend to aggregate if there is no surfactant compared. Another researcher used fractional factorial design approach to propose suitable condition for CNT/water nanofluid production [53]. A group of researchers used gemini surfactant with high concentration to give adverse influence on the MWCNT thermal conductivity enhancement [54]. A previous researcher utilized ultrasonic probe/SDS surfactant and ultrasonic bath/SDS surfactant to investigate the effect of using five different CNT nanofluid on thermal conductivity [55]. A researcher concluded that the thermal conductivity enhancement was about $19.73 \%$ for using 0.45 vol.\% MWCNT/ethylene glycol (30\%)/water (70\%) nanofluid with SDBS surfactant at $40{ }^{\circ} \mathrm{C}$ [56].

Based on a study, the effect of using CNT/ethylene glycol/water nanofluid with three types of surfactants (PVP), (GA) and (CTAB) on the stability and thermal conductivity of nanofluids [57]. The stability results were presented by zeta potential measurement and observation methods. The results indicated that $0.01 \mathrm{wt}$ \% of CNT nanofluid with $0.01 \mathrm{wt} \%$ CTAB gives maximum zeta potential values. But the $0.5 \mathrm{wt}$ \% of CNT nanofluid with Gum Arabic will perform a thermal conductivity enhancement about $25.7 \%$ [58].

In addition, it should be noted, the sedimentation of nanoparticles is less important for turbulent flow regime due to the higher imposed shear which breaks down the possible agglomerated particles, therefore, turbulent flow condition in the present investigation helps to provide a stable solution during the experiments [59]. Also, the stability of nanofluid depends on surfactant (SDS) and $\mathrm{pH}$ value of base fluid apart from sonication time.

High surface activity and nanoparticles surface area are the main cause of the sedimentation due to the Brownian motion and Vanderwaals forces, which directly result in the clustering of nanoparticles. However, addition of surfactant will generate an interfacial film surrounding nanoparticles will be formed as a result of adsorption of dispersant on the interface [60]. To produce a stable nanofluid, either the particles size should be small enough to be suspended by Brownian motion or the particles must be protected against aggregation by electric charge or other protective coatings such as surfactants.

The morphology and chemical structure of the nanoparticles and base fluids are strongly effects on the nanofluid stability [61]. Moreover, in order to achieve optimized thermal property performance, we must obtain a durable and stable nanofluid is a key factor [62]. In addition, the very small size of the nanoparticles should markedly improve the stability of the suspension [63].

\section{EFFECT OF SURFACTANT ON THE NANOFLUIDS STABILITY}

\subsection{A Stability Mechanisms}

The nanparticle aggregation can be hampered the stability of the nanofluid. However, to avoid this aggregation, there are two methods of mechanical dispersion and chemical dispersion method [64]. The mechanical dispersion method included the decreasing the van der Waals forces by introducing external repulsive forces such as steric, electrosteric or electrostatic forces. If this force was over repulsive force, then the nanoparticles aggregate in clusters. Therefore, the increasing the repulsive forces over attractive forces can avoid nanoparticle aggregation and reach stability. The chemical dispersion method used to enhance the chemical compatibility of the nanoparticles with base fluid by using surface active agents (surfactants) to enhance the adhesion or wetting characteristics and minimize the nanoparticles tendency to agglomerate in solvent [65]. There are two mechanisms to achieve the nanofluids stabilization by using surfactants [66]:

a) Electrostatic stabilization using ionic surfactants

b) Steric stabilization using nonionic surfactants

In order to minimize the effects of poor dispersion, steric barriers (surfactants) are typically employed. The surfactant molecules create a barrier for agglomeration prevention and particle solubility [67]. The effect of surfactant on the characteristics of stability CNT nanofluids of case of without surfactant is given by Fig.4. The results showed that to produce a stable nanofluid sample, the sonication process alone is not enough. Also, the worst stability in terms of particle sedimentation found when using the sample with $0.05 \mathrm{wt}$. \% of MWCNT exhibited. The sample showed sedimentation of particles even right after the sonication process [68].

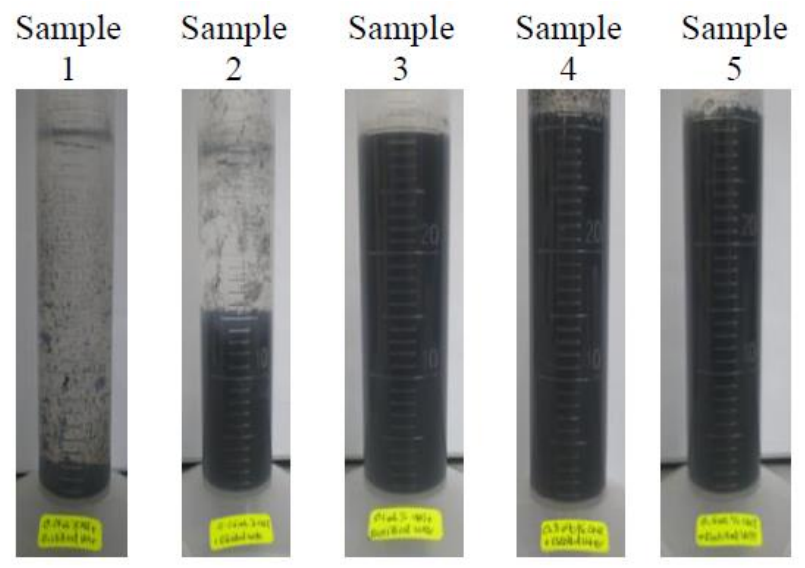

a) Without PVP surfactant

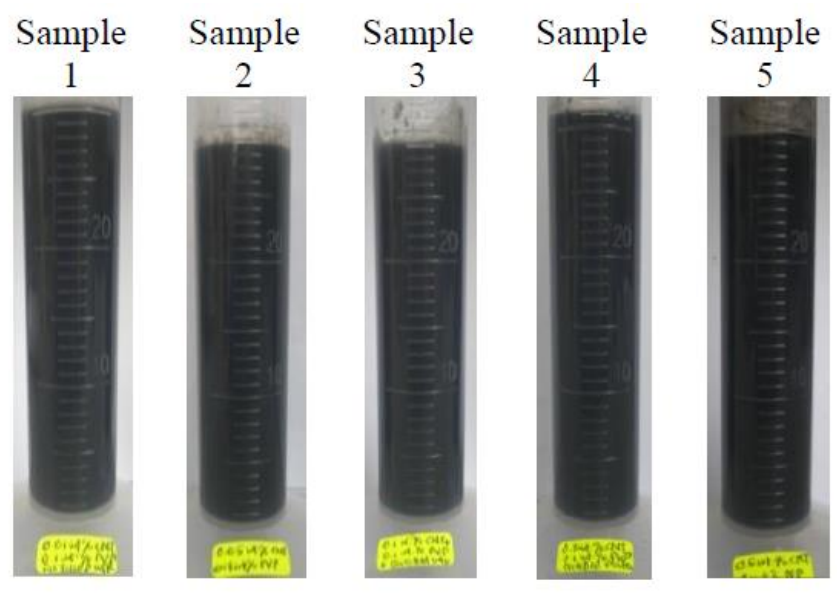

b) With PVP surfactant

Figure 4: Stability observation for carbon nanotube nanofluids observation (after 1 month) [68]. 
A researcher examined the stability of many nanofluids such as (nanoparticles: fullerence, MWCNT, silicon dioxide and copper oxide; base fluid: ethylene glycol, water and oil) by utilized using spectral analysis [69]. They showed that the surfactant addition can enhance the suspensions stability.

To obtain low viscosity and high thermal conductivity in order to enhance heat transfer of the suspensions, larger nanoparticles should be used [71]. But, the drawback of using larger nanoparticles is the nanofluids potential instability. The settling velocity of nanoparticles $\left(V_{s}\right)$ can be estimated by Stokes law that given by a researcher [70]:

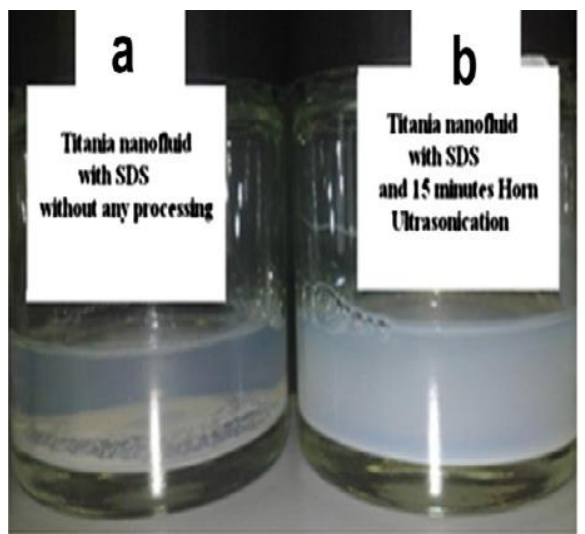

Figure 5: Sedimentation rate of $\mathrm{TiO}_{2}$ /water nanofluid after 1 week with and without SDS surfactant and without any ultrasonication [72].

Figure 6 showed the effect of using surfactant addition on dispersion of $\mathrm{TiO}_{2}$ /water nanofluid by utilizing ultrasonic bath. Samples a and b were prepared by dispersion of 0.1 wt. $\% \mathrm{TiO}_{2}$ with $3 \mathrm{~h}$ ultrasonic bath, but sample b prepared with the same weight concentration of SDS in its recipe.
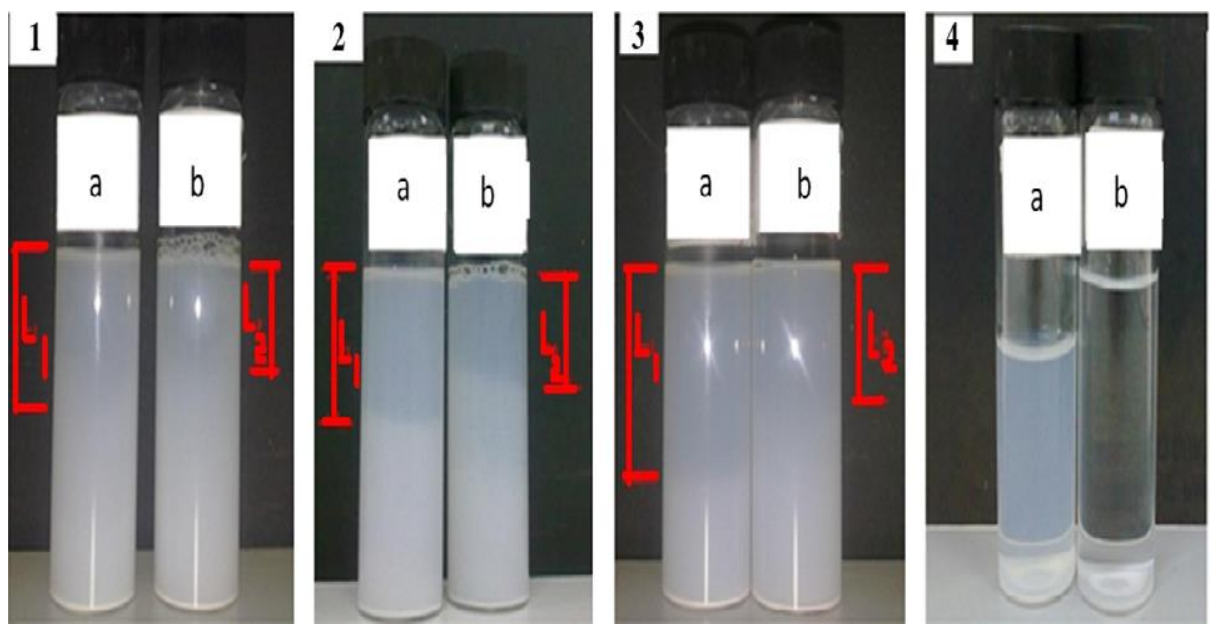

Figure 6: The effect of $3 \mathrm{~h}$ ultrasonic bath and surfactant addition on $0.1 \mathrm{wt} . \%$ titania nanofluid; sample a: without SDS, sample b: with SDS; (1) 3 days after preparation; (2) 4 days after preparation; (3) 1 week after preparation; and (4) 1 year after preparation [72].

A researcher studied the $\mathrm{CuO} /$ water nanofluid with using polyvinylpyrolidone (PVP) as the dispersant [73]. The nanofluid stability measured by zeta ( $\zeta$ ) potential and absorbency under different $\mathrm{pH}$ values and PVP surfactant concentrations and measuring the nanofluid thermal conductivities. The results concluded a good stability of about a week, when using nanofluid with PVP surfactant. Moreover, several researchers concluded that the surfactants addition was achieved homogeneous disperse nanoparticles in the base fluids $[74,75]$. The effects of PVP surfactant concentrations on the nano-suspension stability were studied by a researcher $[76,77]$.

A researcher showed that the thermal conductivity of $0.3 \%$ copper/ethylene glycol nanofluid is decreased with time, where the fresh nanofluids has higher thermal conductivities than that stored up to two months [78]. Based on a research, the stability of $\mathrm{Al}_{2} \mathrm{O}_{3}$ nanofluid with time. They found that nanofluid that kept for 30 days will get settlement compared to fresh nanofluid [79]. A researcher concluded that there is a harmful effect of increasing the surfactant quantity on chemical stability and thermal properties and thus it is strongly recommended to control the

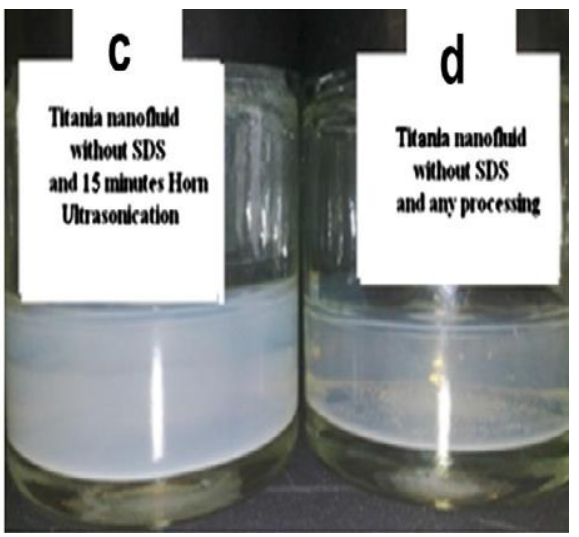

The results showed that the most stable suspension is given by applying 3-h ultrasonic bath with the addition of $0.1 \mathrm{wt}$.\% surfactant and it given the highest thermal conductivity.

Where $\mathrm{g}$ is the acceleration of gravitational, $\left(\rho_{\mathrm{p}}\right)$ is the particles density, $(\rho)$ is the fluid density; $(b),(\mu)$ is the suspension viscosity and $(r)$ is the radius of particles. Also, the increasing the suspension temperature will . energy. In addition, Fig.5 presented the samples nanofluid stability for 15 min by ultrasonic will decrease the sedimentation rate especially if it was accompanied by SDS surfactant addition [72]. 


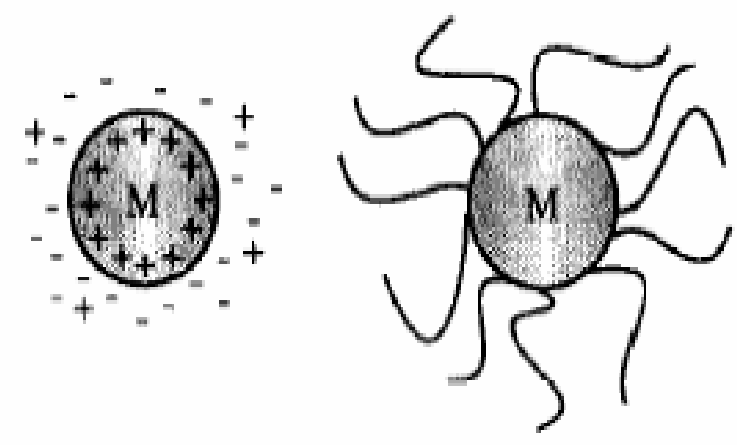

Figure 7: Schematic illustration for (A) electrostatically stabilized metal (M) particle and (B) a sterically stabilized metal particle. [82].

Stabilization of the nanofluids suspensions is therefore achieved by the addition of small nanoparticle concentrations, which induce an effective repulsion, counteracting the Van der Waals attractions between the particles. In numerious literatures, (SDBS) was used as the surfactant, while the additions of either sodium hydroxide $(\mathrm{NaOH})$ or hydrochloric acid $(\mathrm{HCl})$ were used as a $\mathrm{pH}$ control nanofluid. However, there are several problems of using increasing the surfactant concentrations in the nanofluids such as increasing nanofluid viscosity, reducing the heat transfer properties, foam generation and contamination [83]. Long term physical and chemical stability of nanofluids is an important practical issue because of aggregation of nanoparticles due to very strong Vander Walls interactions so the suspension is not homogeneous. A group of researchers found that $\mathrm{Al}_{2} \mathrm{O}_{3}$ nanofluids kept after 30 days exhibit some settlement compared to fresh nanofluids [84]. A researcher found that nanotube concentration and stabilizing surfactant volume affects the thermal conductivity of MWCNT nanofluids [85].

\section{SURFACTANTS IN NANOFLUIDS}

Formulating stable nanofluids suspensions is very difficult, and the control of nanofluids properties such as viscosity, thermal conductivity and wettability for heat transfer applications. Several researchers have experienced poor stability of nanofluids with sedimentation characteristics occurring [86]. The addition of surfactants to the nanofluids during the formulation process has been shown to effectively disperse nanoparticles in the base fluids [87]. The aggregation of the nanoparticles in the preparation the nanofluids would not only cause by the nanoparticles clogging and settlement, but also affect the thermal properties [88]. The dispersion stability of $\mathrm{a}-\mathrm{Al}_{2} \mathrm{O}_{3}$ nanofluids with different mass fractions of surfactants of PAA, CTAB and SDBS was investigated by a researcher [89]. It was found that the dispersion of $\mathrm{Al}_{2} \mathrm{O}_{3}$ suspensions firstly increased to a maximum and then decreased with the increase of surfactant concentration. A scholar used copper/ethylene glycol nanofluid with PVP surfactant. The results concluded that the stability of copper nanofluid can be significantly improved by adding of PVP surfactant [90].

\subsection{A Surfactants Effect on Nanofluids Thermal Conductivity}

As presented above, the addition of surfactant to the nanofluids suspension has a great effect on the stability and thermal properties of nanofluids. In this section, we will discuss the effect of using various surfactant on the thermal conductivity of the nanofluids. There are a few available thermal conductivity models for nanofluids with surfactants. Thus, there is a great need to state new thermal conductivity models to describe the effect of surfactants on the thermal conductivity of the nanofluids [91].

A researcher utilized $\mathrm{TiO}_{2}$ nanofluids and suitable $0.01 \%$ surfactants and found that the enhancement of thermal conductivity was about $33 \%$ when using $5 \%$ of nanoparticles in base fluid [92]. Although several forms of thermal conductivity models for nanofluid have been established, few models for nanofluids containing surfactants are found. A researcher presented some of the thermal conductivity models that described the spherical and columnar $\mathrm{TiO}_{2}$ nanofluid. The present models achieve higher accuracy and precision for all the four kinds of applications. Thus, for spherical $\mathrm{TiO}_{2}$ nanofluid, the thermal conductivity model was given by a researcher:

$$
k_{e f f}=\frac{\left(k_{p}-k_{l r}\right) \emptyset k_{l r}\left(2 \beta_{l}^{3}-\beta^{3}+1\right)+\left(k_{p}+2 k_{l r}\right) \beta_{l}^{3}\left[\varnothing \beta^{3}\left(k_{l r}-k_{f}\right)+k_{f}\right]}{\beta_{l}^{3}\left(k_{p}+2 k_{l r}\right)-\left(k_{p}-k_{l r}\right) \emptyset_{p}\left(2 \beta_{l}^{3}+\beta^{3}-1\right)}
$$

With surfactants h=l but without surfactants $h=\sqrt{2 \pi \sigma}$

And thermal conductivity model for columnar $\mathrm{TiO}_{2}$ nanofluids is given by:

$k_{e f f}=k_{e f f 2} \frac{2 \pi r H}{2 \pi r^{2}+2 \pi r H}+k_{e f f 2} \frac{R_{X}}{R_{Z}} \frac{2 \pi r^{2}}{2 \pi r^{2}+2 \pi r H}$

Where

$k_{e f f 2}=\frac{\left(k_{p}-k_{l r}\right) \emptyset k_{l r}\left(2 \beta_{l}^{2}-\beta^{2}+1\right)+\left(k_{p}+k_{l r}\right) \beta_{l}^{2}\left[\varnothing \beta^{2}\left(k_{l r}-k_{f}\right)+k_{f}\right]}{\beta_{l}^{2}\left(k_{p}+k_{l r}\right)-\left(k_{p}-k_{l r}\right) \emptyset_{p}\left(\beta_{l}^{2}+\beta^{2}-1\right)}$

Where

$\beta=1+h / r$

$\beta_{l}=1+h /(2 r)$

$k_{l r}=2.5 k_{f}$

$R_{z}=\frac{H}{k_{p} \pi r^{2}+k_{f}\left(H^{2}-\pi r^{2}\right)}$

$R_{z}=\frac{H-\pi r / 2}{k_{f} H^{2}}+\frac{\pi r / 2}{2 k_{p} r H+k_{f}\left(H^{2}-2 r\right) H}$

With surfactants h=l but without surfactants $h=\sqrt{2 \pi \sigma}$

A researcher studied the effect of both the $\mathrm{pH}$ control and addition of surfactant to enhance the thermal conductivity of $\mathrm{Cu} /$ water nanofluid [93]. Fig. 8 plotted the ceffect of using three types of on PVP, GA and CTAB surfactants on the spherical $\mathrm{TiO}_{2}$ nanofluid thermal conductivity. The results indicated that the thermal conductivity is greatly increased, when added the CTAB surfactant as dispersant.

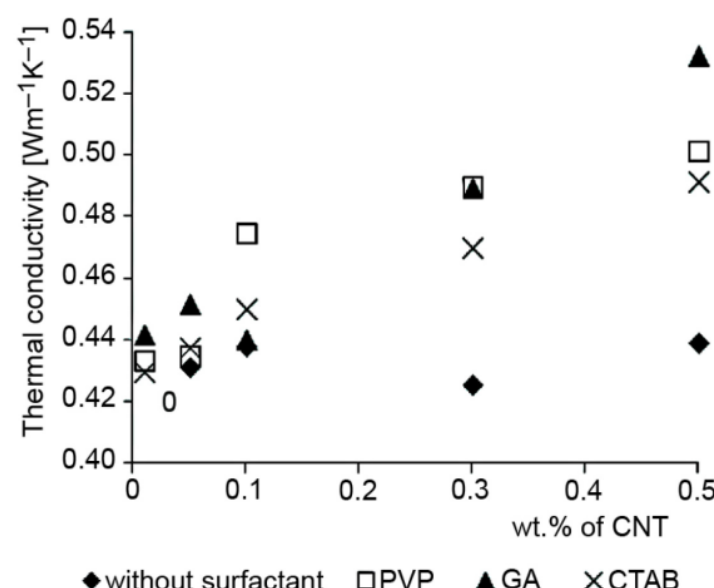

Figure 8: Effect of surfactant on the CNT nanofluids thermal conductivity [35]. 
Also, a researcher concluded that the surfactants addition of would will lead to decrease the nanofluids thermal conductivity, but the dispersion techniques have no obvious effect on the thermal conductivity enhancements [94]. A researcher concluded that for the CNT based nanofluids of without surfactant, there is no substantial thermal conductivity enhancements. Moreover, they showed that improvement of thermal conductivity of CNT nanofluid by using surfactants. A surfactant improves the stability of a nanofluid by uniform dispersion of particles. A surfactant can adsorb gas in a liquid-gas interface and decrease the interfacial tension. Some surfactants may flocculate in the bulk solution [95]. However, a researcher used larger sized nanoparticles and obtain an enhancement similar to that founded earlier by another researcher who concluded that the thermal conductivity enhancement caused by the nanoparticles Brownian motion due to surfactant addition [96,97]. Also, both researchers indicated that for the suspensions containing surfactants the higher conductivity improvement though particle size of solids were different in both cases [98]. A researcher used 42-nm-sized $\mathrm{Al}_{2} \mathrm{O}_{3}$-water nanofluids with using surfactant of (SDBS) and given the enhancement was about $10 \%$. Recently, a researcher used $\mathrm{Al}_{2} \mathrm{O}_{3}$ - water nanofluid and using surfactant of oleic acid in a car engine coolant and obtain an enhancement of $10.41 \%$ for 3.5 but the enhancement increased to $13 \%$ for $5 \mathrm{vol}$. \% of $\mathrm{Al}_{2} \mathrm{O}_{3} / \mathrm{EC}$ nanofluid. Figure 9 showed the thermal conductivity enhancement with good stability [99].

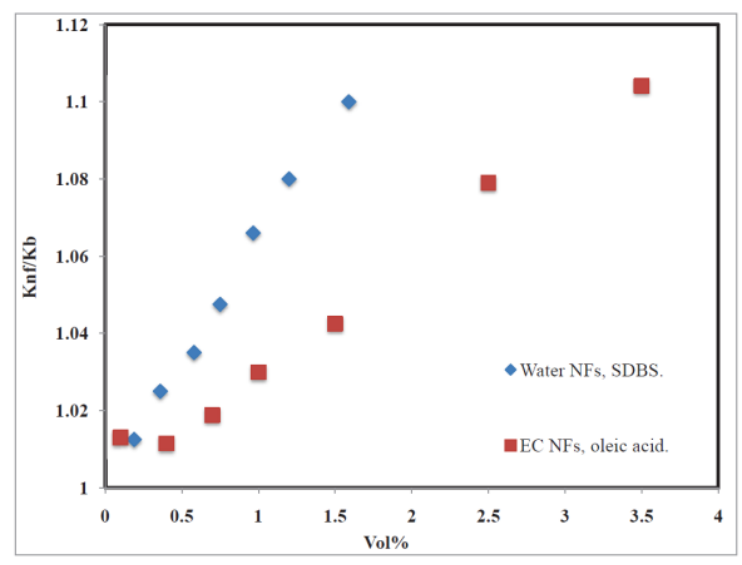

Figure 9: Effect of additives on thermal conductivity of $\mathrm{Al}_{2} \mathrm{O}_{3} /$ Water with SDBS and $\mathrm{Al}_{2} \mathrm{O}_{3} / \mathrm{EC}$ with oleic acid [25].

A recent researcher used carbon nanotubes water-based nanofluids to study different kind of surfactant such as ( $\mathrm{N}_{1}$ with SDBS, $\mathrm{N}_{2}$ with Lignin, $\mathrm{N}_{3}$ with Sodium polycarboxylate) on thermal conductivity enhancement of nanofluids [100]. Fig.10 showed that surfactant nature do not influence thermal conductivity enhancement except at higher volume fraction for SDBS. This can be explained by the dispersion state of CNT with this surfactant at this volume fraction, as NF appears mainly in the form of aggregates.

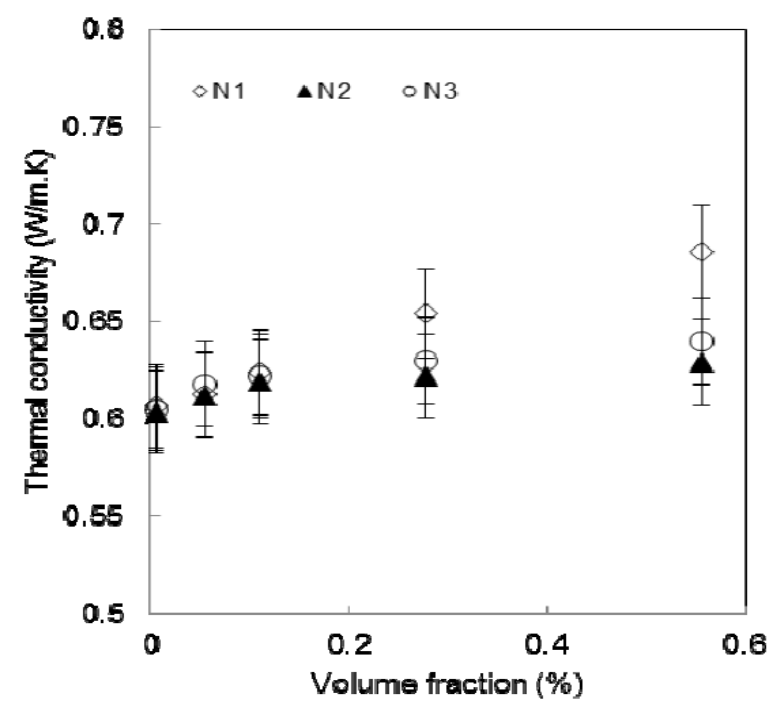

Figure 10: Surfactant ( $\mathrm{N}_{1}$ with SDBS, $\mathrm{N}_{2}$ with Lignin, $\mathrm{N}_{3}$ with Sodium polycarboxylate) on thermal conductivity enhancement of nanofluids [100].

The effect of surfactant on thermal conductivity of CNT nanofluids were also investigated by a scholar [101]. In fact, carbon nanotube is very promising due to their high thermal, electrical and mechanical properties. They found that the using surfactant within the base fluid is generally functionalized to improve the solubility and stability of the nanofluids to prevent agglomeration and sedimentation.

A researcher studied the effect of surfactant addition on the nanofluids thermal conductivity and obtain a perfect nanoparticles dispersion with addition of SDS surfactant [102]. Furthermore, concentration of $\mathrm{pH}$ and PVP, optimum $\mathrm{CuO}$ volume fraction of $6 \%$ was obtained, in which, the thermal conductivity enhancement is $17 \%$ at $25^{\circ} \mathrm{C}$.

Another researcher indicated that the addition of surfactant with high concentration has a negative factor in enhancing the nanofluids thermal conductivity [103]. A researcher used MWCNT nanofluid with SDS and SDBS surfactants to study the thermal conductivity and stability [104]. They indicated that CNTs/surfactant had higher thermal conductivity by utilizing an optimal mixture weight was 0.5 wt. \% CNTs nanofluid with 0.25 wt. \% SDBS. Fig. 11 presents the thermal conductivity ratio of the nanofluids of $\mathrm{CuO} / \mathrm{Al}_{2} \mathrm{O}_{3}$ water nanofluids as the function of SDBS concentrations as well as nanoparticles weight fractions. Their results showed that the increasing the SDBS weight fraction up to $0.1 \mathrm{wt} . \%$ and 0.15 wt. $\%$ for $\mathrm{Al}_{2} \mathrm{O}_{3}$ and $\mathrm{CuO} /$ water respectively, the thermal conductivity ratio increased slowly. But, the thermal conductivity rapid decreases when adding more surfactant into the nanofluids system. Moreover, the optimizing and controlling the SDBS surfactant weight concentration and $\mathrm{pH}$ will lead to adequate the electrostatic repulsion force between particles, to prevent from the collision and attraction between particles triggered by Brownian motions. 

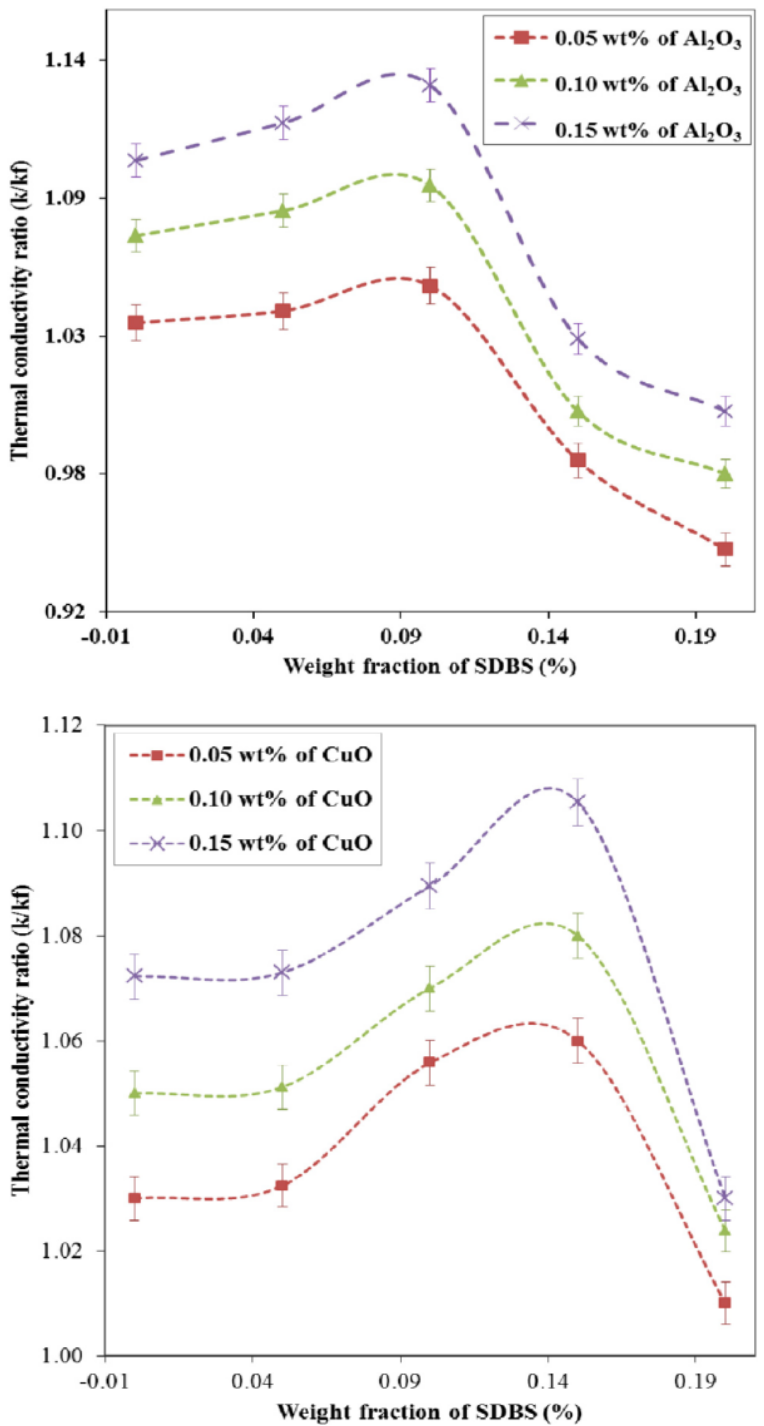

Figure 11: Effect of SDBS additive and nanoparticles weight fraction on thermal conductivity ratio of $\mathrm{CuO} / \mathrm{Al}_{2} \mathrm{O}_{3}$ water nanofluids at a constant temperature of $298 \mathrm{~K}$ [105].

Moreover, a scholar concluded that the nanofluids thermal conductivity will be decreased by addition of polymeric surfactants [106]. Another researcher studied $\mathrm{Al}_{2} \mathrm{O}_{3}$-water nanofluid with two kinds surfactant mass fractions of SDS and PVP surfactants on the thermal conductivity and stability of the nanofluids [107]. Their results showed that the surfactant addition plays an important role in nanoparticles dispersing and enhancing the nanofluid stability where the non-ionic PVP surfactant shows better positive effect than anionic SDS surfactant. Fig. 12 presented the nanofluids thermal conductivity with SDS and PVP concentration [108].

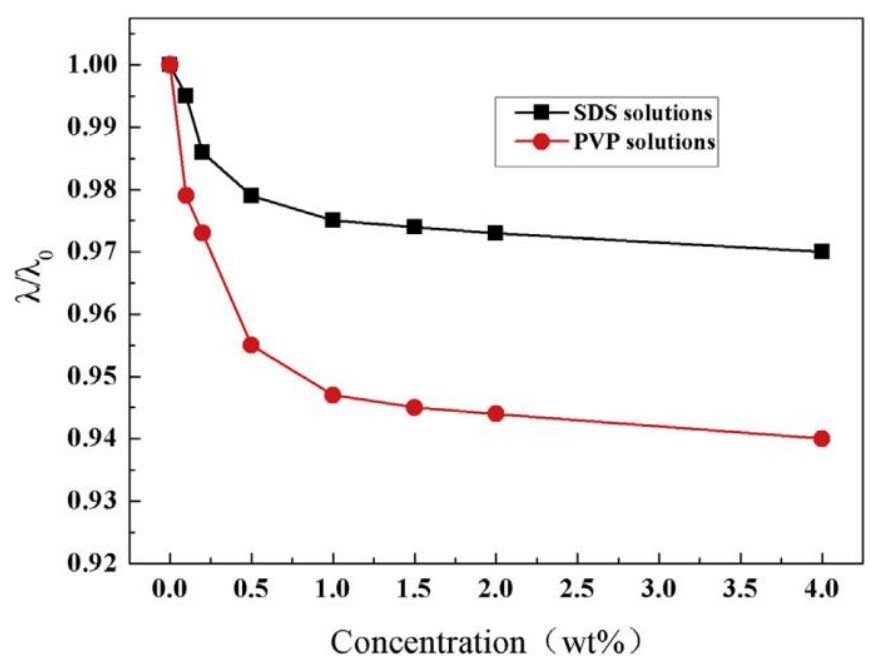

Figure 12: Influence of surfactant concentration on the thermal conductivity of the surfactant solutions at room temperature [107].

Also, Figure 13 plotted the effect of SDS surfactant concentration on the thermal conductivity ratio of $\mathrm{Al}_{2} \mathrm{O}_{3}$-water at room temperature. The results showed that with increasing of both SDS and PVP concentration, the thermal conductivity ratios increased at the beginning, but it decreased after the concentration of surfactants reaches a stable value. 

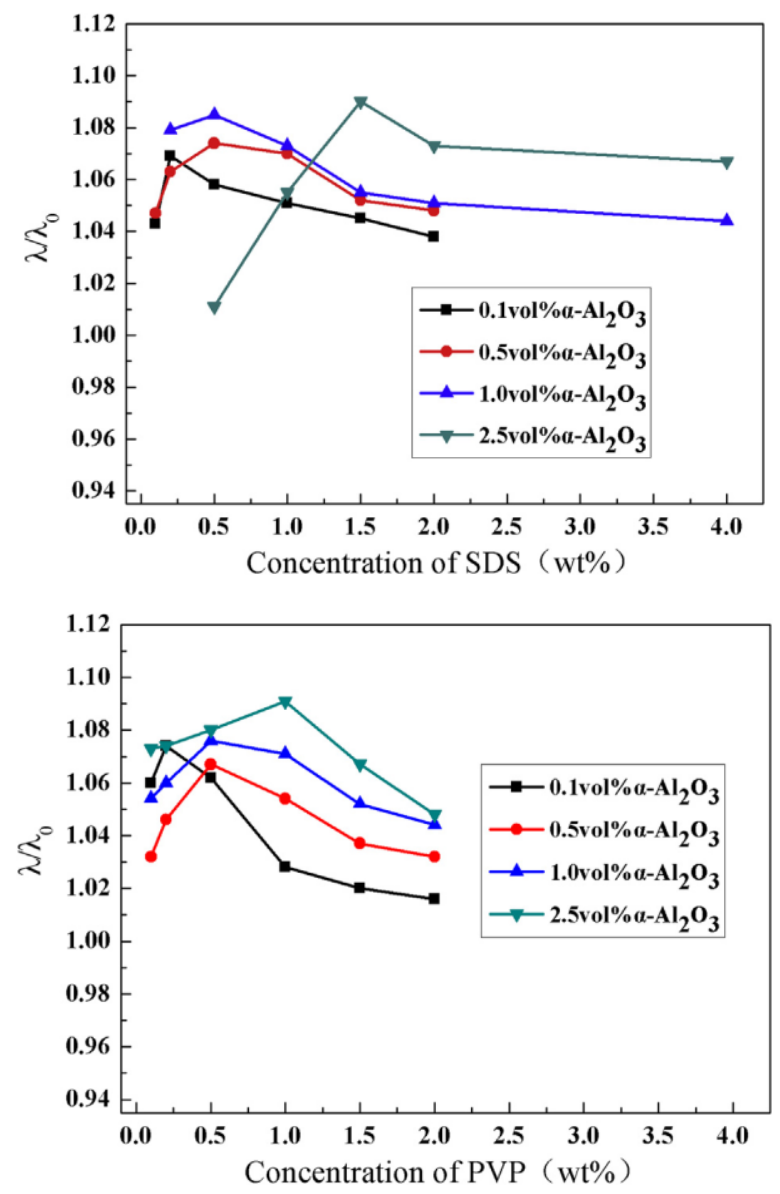

Figure 13: Efeect addition SDS and PVP surfactants concentration on the thermal conductivity of $\mathrm{Al}_{2} \mathrm{O}_{3} /$ water [107].

Based on a study, the effect of addition various surfactants such as SDS, SDBS, CTAB, and PVP on the nanofluids thermal conductivity. They concluded that the using ionic surfactant will lead to achieved higher thermal conductivity ratios than those of non-ionic surfactant. The thermal conductivity of surfactants is significantly lower than EC and water. Although, the surfactants addition is enhancing the viscosity of nanofluid, but it reduces the thermal conductivity of it. Finally, a researcher examined the effect of presence of surfactants (PEG, PAA) in the nanofluids and they found that the surfactants could improve the thermal conductivity and stability of nanofluids [109].

\subsection{Surfactants Effect on the Nanofluid Dynamic Viscosity}

The prepared nanofluids must have low viscosity, good fluidity, high stability, and high thermal conductivity, and it would have potential applications as coolants in advanced thermal systems applications. The advantages of well dispersed nanofluids to be used as coolants are (i) higher heat transfer surface area, (ii) lower viscosity and lesser pumping power, and (iii) good colloidal stability due to the smaller size of aggregates [110]. The relative viscosity is the ratio of effective viscosity of nanofluid and the pure base fluid, as a function of volumetric particle concentration as shown in Fig. 14. A researcher showed that the nanofluids viscosity is much higher than that predicted by the Einstein eq., which shows strong effect of interactions of the nanoparticles. Viscosity of nanofluids increases dramatically, with increase in particle concentration. But with addition of RK7 surfactant, the viscosity was drastically decreased in ZnO-RK7 nanofluid shown as green colour which touches to the Einstine model black dotted lines.

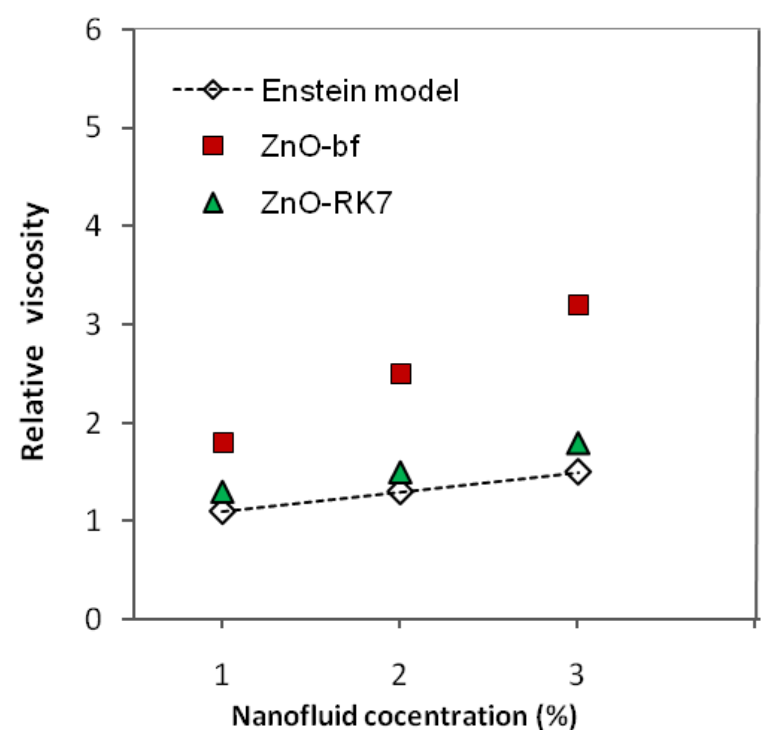

Figure 14: Relative viscosity of $\mathrm{ZnO}-\mathrm{bf}$ and $\mathrm{ZnO}-\mathrm{RK} 7$ nanofluids as a function of nanoparticle volume concentration [30]. 
A researcher used CNT/water nanofluid with acid treatment TCNT surfactant and PCNT surfactant to investigate the nanofluid viscosity [111]. They indicated that the nanofluid with TCNT surfactant have much smaller viscosity than those with surfactant PCNT. Thus, the surfactant addition will lead to increase or decreas $\mathrm{pH}$ value and cause weaker repulsion between particles and lower surface charge [112,113]. The stability and rheology of concentrated $(>50 \%) \mathrm{TiO}_{2}$ dispersions was investigated [114]. They showed that the viscosity decreased with increasing surfactant (SDS).
A scholar studied the pressure drop of CNT-water nanofluids that flowing through a horizontal tube. Their results showed that the nanofluids prepared by the acid treatment (TCNT) had much smaller viscosities than those made with surfactant of (PCNT).

Figure 15 presented the viscosity of nanofluid with SDBS surfactant and weight concentrations of nanoparticles for $\mathrm{Al}_{2} \mathrm{O}_{3}$ and $\mathrm{CuO}$-water nanofluids at a constant shear rate of $134 \mathrm{~S}^{-1}$ and $150 \mathrm{~S}^{-1}$. The results showed that the viscosity decreases at beginning.
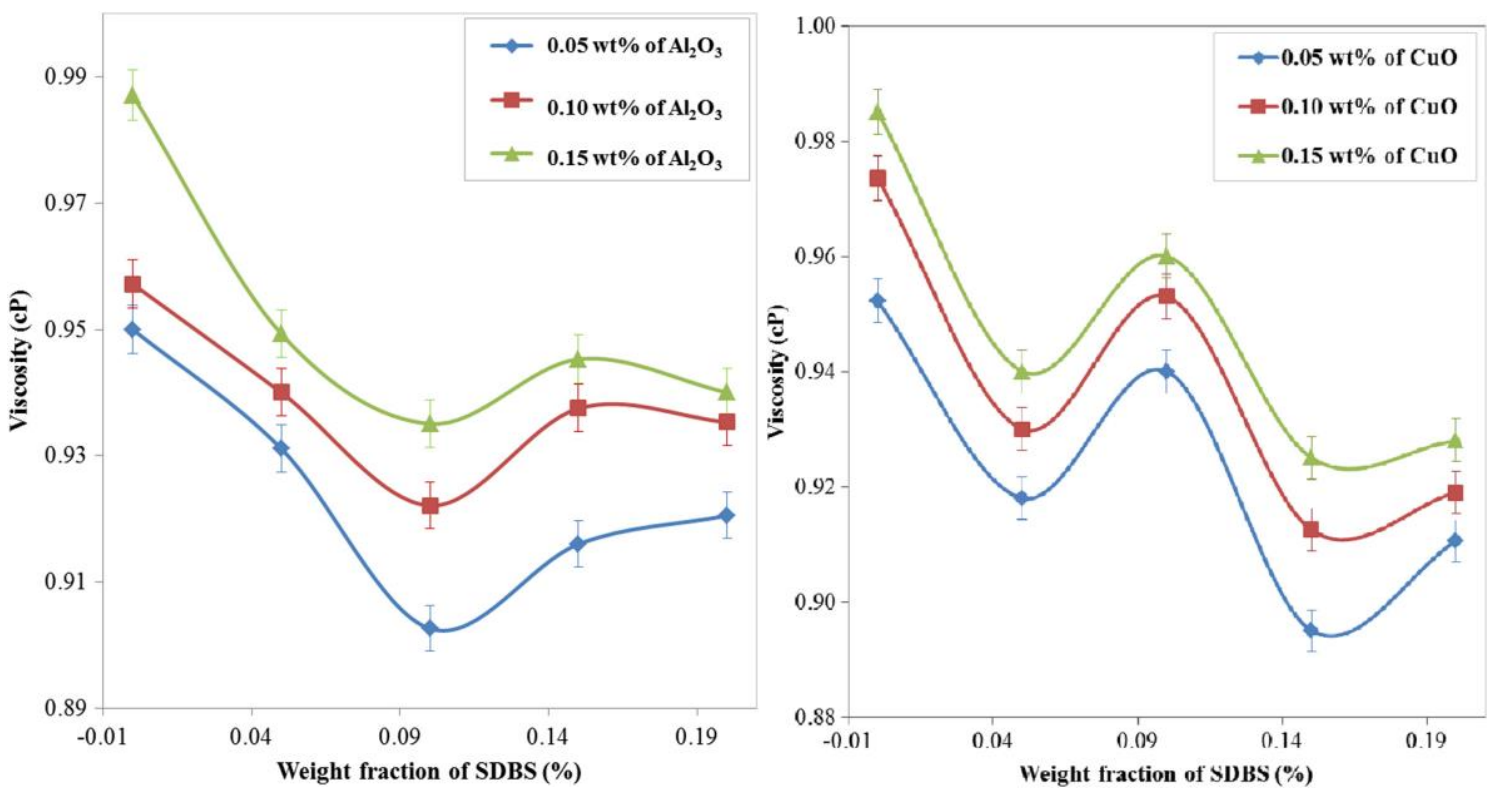

Figure 15: Variation of $\mathrm{Al}_{2} \mathrm{O}_{3} /$ water nanofluid viscosity with SDBS concentration [105].

\subsection{Surfactants Effects on the Zeta Potential and pH Values}

There are two different liquid layer regions surrounding the nanoparticles in the base fluids; an inner region (stern layer) where the ions are firmly bounded and an outer (diffuse) region where the ions less strongly associated. Inside the outer layer, there is a notional boundary where there is a stable entity ions and nanoparticles. The potential at this

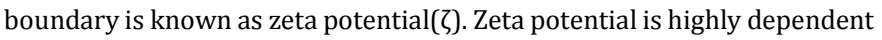
on the $\mathrm{pH}$ value of the solution, due to the $\mathrm{pH}$ value changing will increase the density of electrical charge on the nanoparticles surface. The electrostatic repulsion force between nanoparticles is directly dependent on zeta potential [115].

The isoelectric point (IEP) will use to refer to the effect of nanoparticles surface electrical forces where there is no net electrical charge that carried on a given surface where the negative and positive charges are equal. The electrostatic repulsive between nanoparticles is no important to keep the nanoparticles apart from each other at or near IEP. Therefore, the aggregation and clustering of nanoparticle is weak at $\mathrm{pH}$ values away from IEP and the aggregate tendency far from IEP is nearly zero [116]. Thus, we can use the zeta potential to give direct information about the system of nanofluids suspension stability. If nanoparticles have a magnitude of zeta potential with high positive or negative value, then the nanoparticles tend to repel one another and there is no propensity for the particles to aggregate. The stable and unstable nanofluids is given by dividing line between -30 or $+30 \mathrm{mV}$, where the zeta potentials of nanoparticles that have lower negative value than $-30 \mathrm{mV}$ or have greater positive than +30 $\mathrm{mV}$ are stable nanofluids suspension. Fig. 16 performed the nanoparticle size distribution and zeta potential measurements by using dynamic light scattering method.

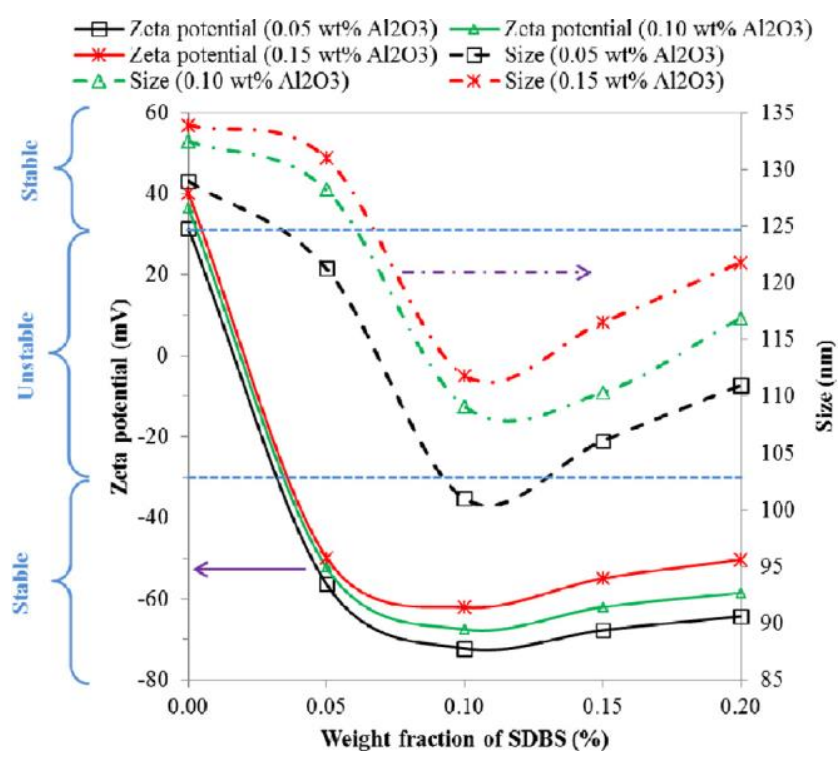

Figure 16: Variation of zeta potential and nanoparticle size of $\mathrm{Al}_{2} \mathrm{O}_{3} /$ water nanofluid with SDBS surfactant [105]. 
Many researchers have examined the effects of time, concentration, temperature, particles type, base fluids and $\mathrm{pH}$ on the zeta potential of nanofluids. It has been found that $\mathrm{pH}$ is the most important factor affecting the dispersion stability and zeta potential of nanofluids. A researcher showed that the zeta potentials of nanofluids containing $\mathrm{Al}_{2} \mathrm{O}_{3}, \mathrm{SiC}$, and $\mathrm{Si}_{3} \mathrm{~N}_{4}$ were changed by the $\mathrm{pH}$ of the nanofluids [117]. They also showed that the zeta potentials increased with increasing the time. Moreover, adding additives such as salts or surfactants may affect the zeta potential. Figure 17 plotted the effect of PVP surfactant at different $\mathrm{pH}$ values on the values of zeta potential of $\mathrm{CuO}$-water nanofluid. The results showed that the operating $\mathrm{pH}$ was selected as $\mathrm{pH}=8$ [118].

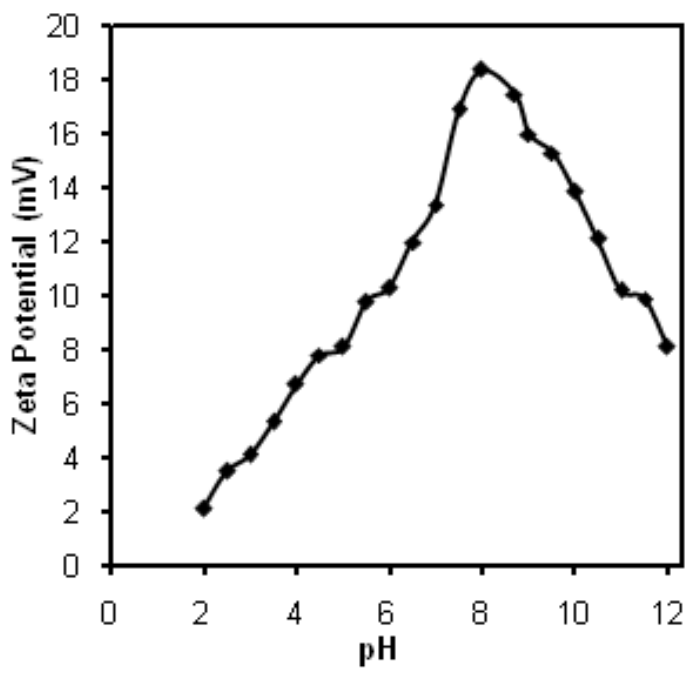

Figure 17: Effect of $\mathrm{pH}$ on the zeta potential of CuO-water nano-suspensions with PVP surfactant [118].

The effect of using CuO/water nanofluid with PVP surfactant on the stability at $\mathrm{pH}=8$ was showed in Fig.18. The results showed that with increasing PVP concentration, the zeta potential firstly enhances and then reduces. The $0.095 \%$ wt. was founded as a PVP optimum concentration where the absorbency and zeta potential are maximal.

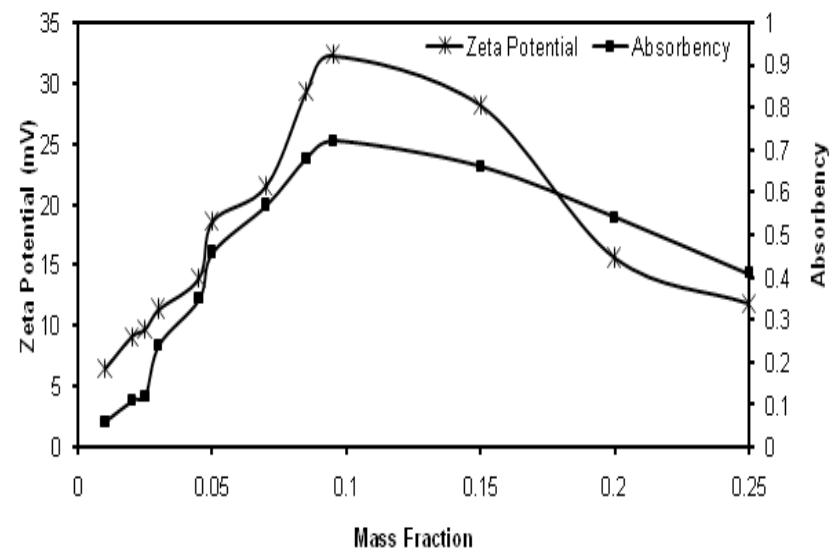

Figure 18: Variation of absorbency and zeta potential of $\mathrm{CuO} /$ water nanofluid with PVP [118].

Also, a researcher used $\mathrm{CuO}$ /water and $\mathrm{Al}_{2} \mathrm{O}_{3}$ /water nanofluids with different concentrations of SDBS surfactant, to study the effect of adding surfactant on the $\mathrm{pH}$ value of the nanofluids as shown in Figure 19. The results showed that the $\mathrm{pH}$ values increased with raising the anionic surfactant concentration.

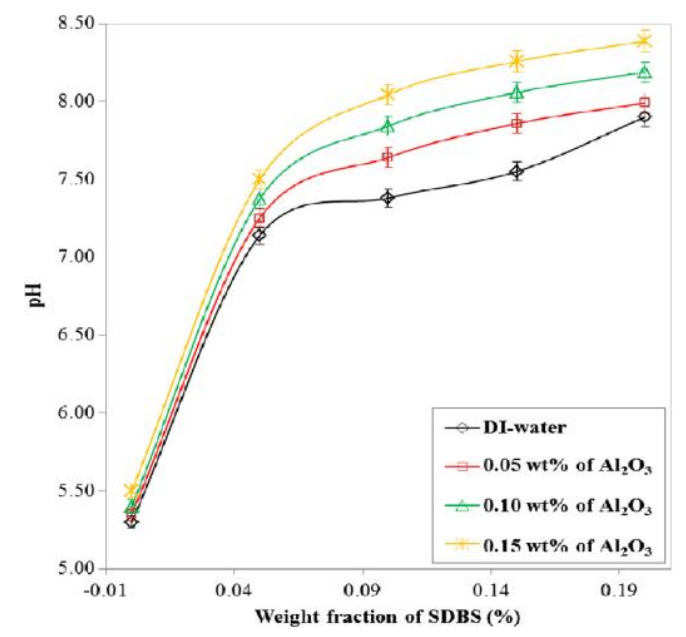




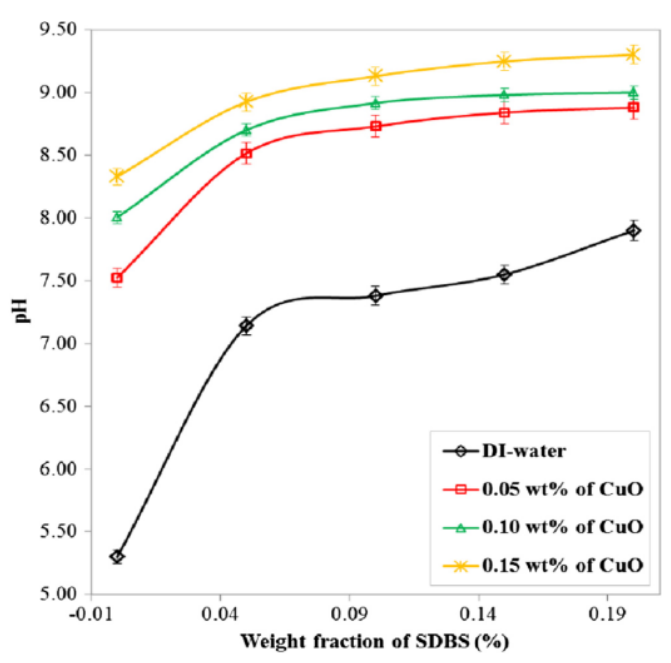

Figure 19: Variation of $\mathrm{pH}$ values of different weight fractions $\mathrm{CuO} /$ water and $\mathrm{Al}_{2} \mathrm{O}_{3}$ /water nanofluids [105].

\subsection{Effects of Surfactants on the Interfacial and Nanofluid Surface} Tension

When adding the nanoparticles to the base fluid by utilizing some type of surfactant molecules, some portion of the total surfactant molecules will be adsorbed at the interface between the solid nanoparticle and liquid base fluid [119]. Surfactants are generally used to increase the nanofluid stabilization. Addition of surfactants will lead to increase the immersion of particles and the surface tension of base fluid will decrease. Through studies of a researcher on the influence surfactants on the nanofluids surface tension [120]. There is an ambiguity with respect to the effect of concentration of the nanoparticles on the behavior of the interfacial tension of these complex fluids [121]. Few studies were reported almost a linear increment of surface tension as increasing the solute phase concentration [122]. Combined interaction between the surfactant and nanoparticles of complex nanofluid system effect on surface tension and when increasing the nanoparticle and surfactant concentration lead to decrease the surface tension [123].

\subsection{Base Fluid and Surfactants Interaction}

The "B effect" has been referred the effect of surfactant molecules on the interfacial energy. Fig. 20 presented the variation of surface tension with adding surfactant of CTAB, SDS and DTAB. The surface tension was measured as $71.03 \pm 0.5 \mathrm{mN} / \mathrm{m}, 50 \pm 0.5 \mathrm{mN} / \mathrm{m}$ and $63 \pm 0.5 \mathrm{mN} / \mathrm{m}$ for three base fluids of DIW, EG and G respectively. The results showed that the base fluids of EG and G with surfactants could not produce a considerable change in the surface tension [124].

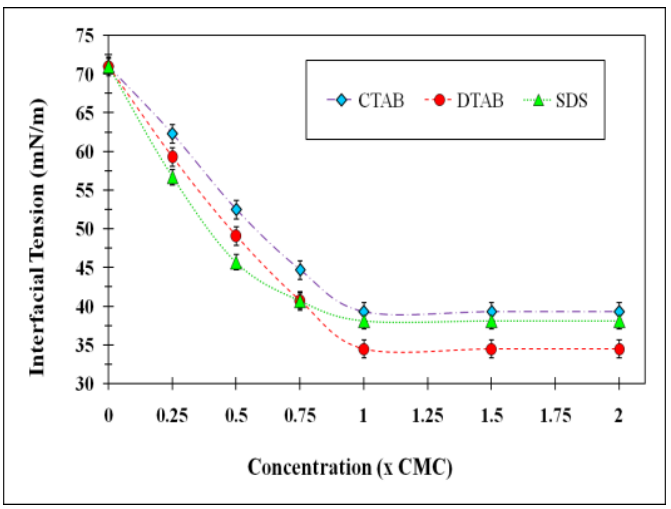

Figure 20: Effect of using CTAB, DTAB and SDS surfactants on the interfacial tension [124].

\subsection{Nanoparticles and Surfactant Interaction}

The interaction between surfactants and nanoparticles is very complicated with consider the interfacial phenomenon. For considering stability issues, the addition of surfactants may be used to prepare nanofluids. Fig. 21 shows the variation of surface tension by using SDS anionic surfactant and DTAB cationic surfactant with different concentrations in order to prepare a stable $\mathrm{CuO}$ nanofluid. The results showed that for long time periods with both the surfactants, the $\mathrm{CuO}$ nanoparticles to be stable.

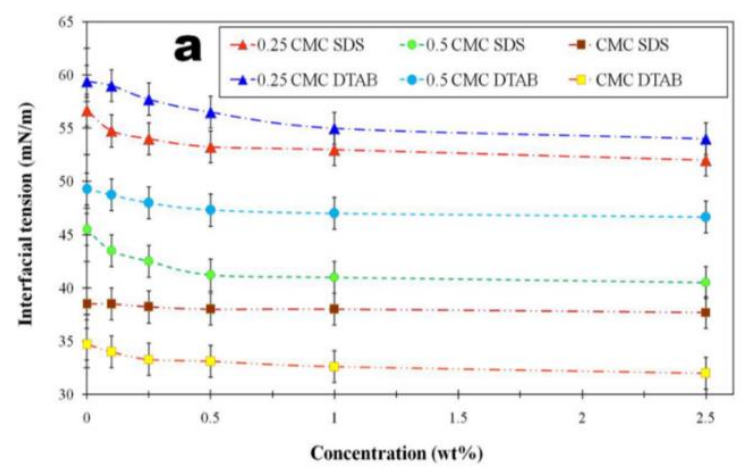

Figure 21: Variation of interfacial tension of nanofluid with different SDS surfactant concentrations for CuO nanofluid [124]. 
For $\mathrm{Al}_{2} \mathrm{O}_{3}$ nanofluid was found to be stable with CTAB as shown in Fig. 22. The figure shows that the surface tension nature will vary with nanoparticles and surfactant concentration and found that this variation to be similar in case of using $\mathrm{CuO}$ and $\mathrm{Al}_{2} \mathrm{O}_{3}$ nanofluid.

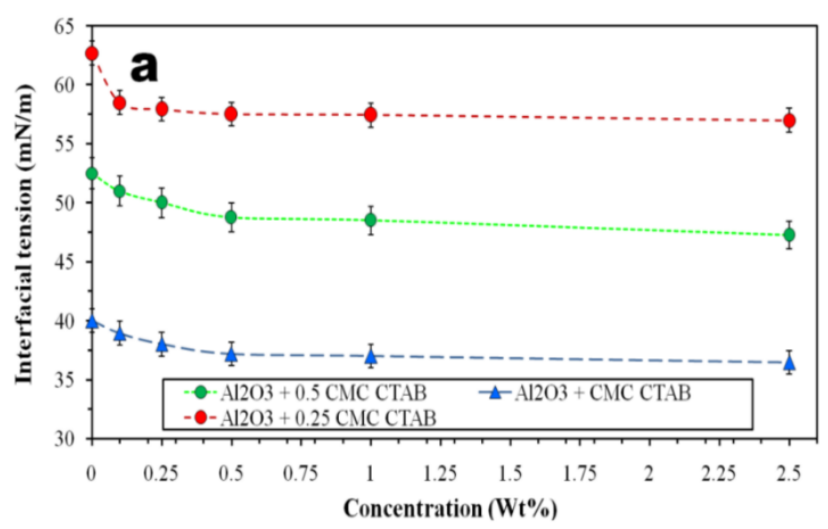

Figure 22: Variation of interfacial tension of nanofluids with different $\mathrm{CTAB}$ surfactant concentration for $\mathrm{Al}_{2} \mathrm{O}_{3}[124]$.

A group of researchers found that the presence of surfactants in the nanofluid is strongly effects on the surface tension of a liquid [125]. Also, a previous researcher showed that the using small amount of surfactant of type CTAB will reduce the surface tension $[126,127]$. However, another researcher showed that the surface tension of the suspension is affected by the surfactants usually employed during nanofluid preparation [128]. Moreover, the experimental results of a recent scholar have been found that the volume fraction intensification has sugnificient effects on the surface tension [129]. Also, the increasing the surfactant concentration will lead to decrease the nanofluid surface tension and increase the solution temperature.
A researcher showed that the using surfactant of NaBDS will lead to reduce the surface tension of CNT/water nanofluid [130]. However, a recent research showed that the utilizing of surfactants of type PVP will not effect on the nanofluid surface tension [131]. Available literature confirms concluded that the nanofluids surface tension depends on suspension temperature, addition of surfactants and nanoparticle concentration [132]. Also, another researcher examined the SWNTs-Water nanofluid with surfactant of NaBDS, to investigate the effect of using surfactant on the surface tension of nanofluids. The variation of nanofluid surface tension with surfactant concentration plotted in Fig. 23. The figure showed that the surface tension decreases clearly with the increase of concentration of surfactant.

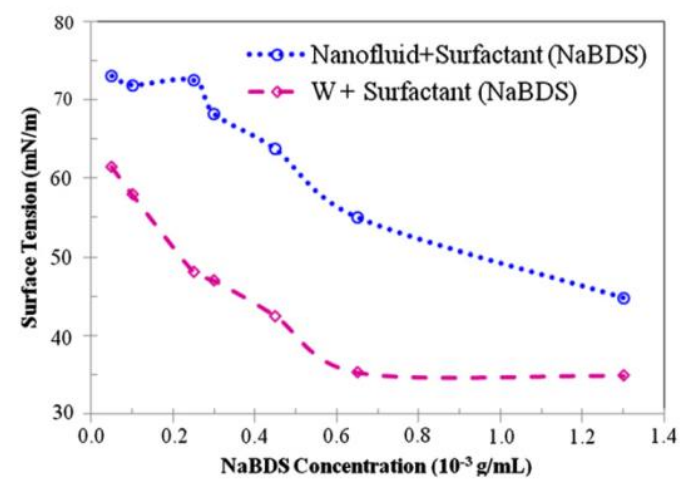

Figure 23: Effect of concentration of surfactant on the nanofluids surface tension [130].

Similarly, a researcher used 0.1 wt. \% n-decane with Sorbitan Oleate surfactant mixture, to study the effect of surfactant addition on the surface tension of nanofluid. The results showed that the surface tension would reduce with increasing the surfactant volume fractions as plotted in Fig. 24 , due to a layer between the particle and the surrounding fluid molecules was formed, as the long-chain surfactant molecules attached to the solid particle. These formed layers will lead to increase the potential between impart a repulsive force between the particles and then will reduce in nanofluid surface tension. Finally, the surfactant behaves like an interfacial shell between the nanoparticles and base fluids and modifies the surface tension of nanofluids [133].

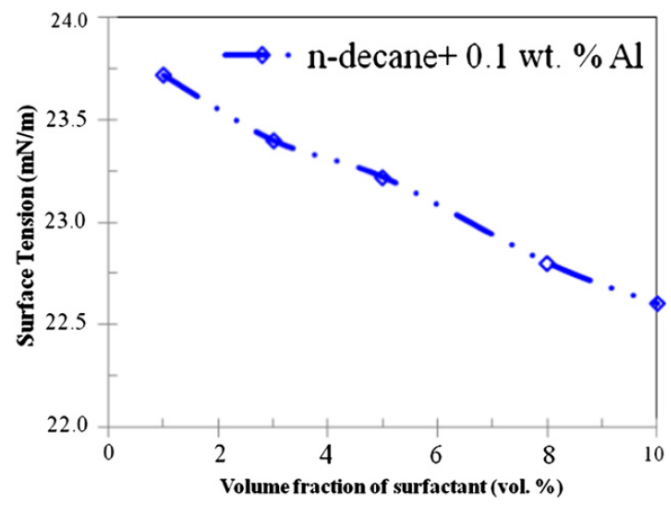

Figure 24: Surface tension variation with surfactant concentration [132] 


\section{SURFACTANTS EFFECT ON HEAT TRANSFER IN NANOFLUIDS}

The enhancements of heat transfer can be applied by increasing heat transfer coefficient, and this achieved by using more efficient heat transfer model or by enhancing the transport properties of the material of heat transfer. However, the coefficients of heat transfer can also be applied by improving the coolant fluids properties. If we predict that the nanoparticles are well dispersed inside the base-fluid, the effective physical properties of the nanofluids mixture like effective density, viscosity, specific heat and thermal conductivity [134,135]. Also, to improve the specific thermal properties of these fluids, additives are often added to liquid coolants [136].
A group of scholars presented an experimental convective heat transfer coefficient of inner tube fluid and outer tube fluids are shown in Fig. 25 Their results showed that improvement in the thermophysical properties of nanofluids with addition of nonionic surfactant $\mathrm{ZnO}$-Rk7. The addition of surfactant Rokanol K7 which helps to binds the nanoparticles together in the fluid medium and prevents the sedimentation which can be indicated that surfactant helps the nanofluids to homogeneously distribute in the heat exchanger. Also, presence of surfactant increases the heat transfer coefficient as compared to without surfactant. Hence, the results fluid increased the heat transfer coefficient in in both the inner $\left(\mathrm{h}_{\mathrm{i}}\right)$ and outer $\left(\mathrm{h}_{\mathrm{o}}\right)$ tube by using nonionic surfactant $\mathrm{ZnO}$-Rk7 nanofluid as compared to $\mathrm{ZnO}$-bf nanofluid.
(A)

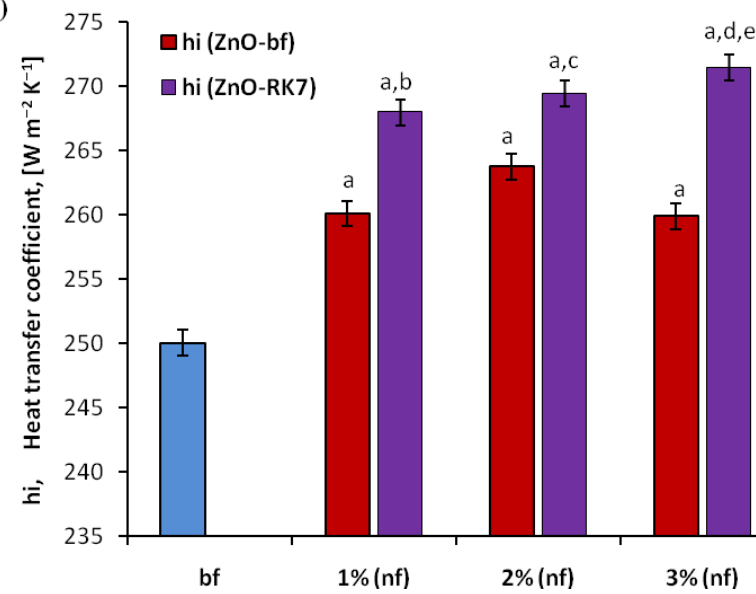

(B)

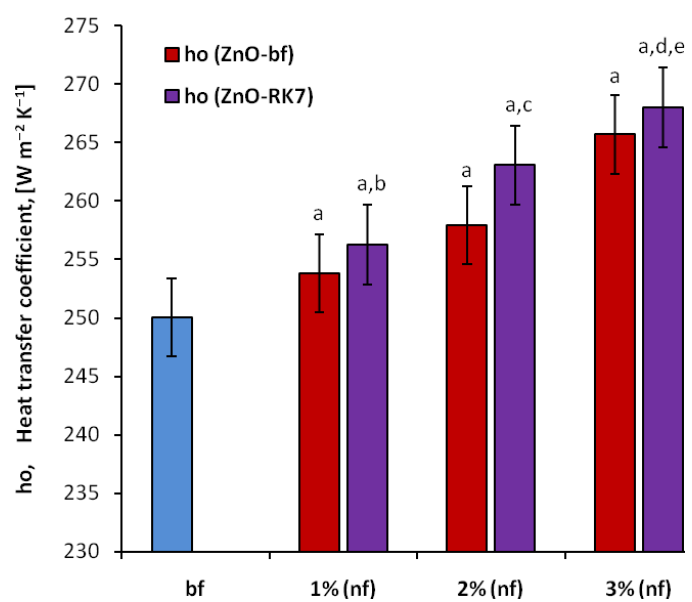

Figure 25: Convective heat transfer coefficient inner tube fluid $\left(h_{i}\right)$ and outer tube fluid $\left(h^{\circ}\right)$ of heat exchanger [30].

For example, about the studies that focused on the effect of surfactant on the heat transfer characteristics of nanofluids [137] showed that the surfactants has significant effects for obtaining a proper stability of nanoparticles suspension without affecting heat transfer performance and nanofluid's thermo-physical properties. But, surfactants have been shown to affect the thermo-physical properties of the dispersed fluid and also the boiling process [138]. Also, a researcher investigated the effect of aggregation and nanofluids stability on performance of heat transfer by using surfactant of SDBS with different concentrations and changing the $\mathrm{pH}$ value [139]. They observed an enhancement in thermal conductivity due to the increasing the nanofluids stability by surfactant addition.

Based on a study the nucleate pool boiling heat transfer of Cu-R113 refrigerant nanofluids with adding three types of surfactants such as SDS, CTAB and Span-80 [140]. They found that the surfactant addition will lead to enhance the heat transfer of nanofluids. Also, they showed that the presence of surfactant enhances the heat transfer by nucleate pool boiling. The surfactant, although essential for the stabilization of single digit-sized nanoparticles, has been identified as a critical component in the heat transfer process of nanofluids. The surfactant can be improved the heat transfer process [141]. Finally, some studies indicated that addition of surfactant will lead to form a high heat transfer thermal resistance in the nanofluids [142]

\section{EFFECT OF SURFACTANTS ON THE ELECTRIC CONDUCTIVITY}

The surfactant can be used to achieve the nanofluids stabilization and it has also a crucial effect on the nanofluids electrical conductivity. For example, the effect of surfactant addition on the electrical conductivity of $\mathrm{Al}_{2} \mathrm{O}_{3}$ /water nanofluid can be plotted in Fig. 10, a researcher used two different concentrations of SDS surfactant [143]. Their results showed that the using of SDS surfactant in nanofluid will lead to improve the electrical conductivity more than SDS/water alone. Moreover, they showed that the using the nanoparticles with higher concentrations $(>0.25 \%)$ will induced to greatly contribute the electrical conductivity of nanofluids. The surfactants addition can be enhance the nanofluids stability but the surfactant can be reduce the electrical conductivity slightly as shown in Fig.26. With the surfactant addition to water, the electrical conductivity was increased significantly while nanofluid density and viscosity are mostly constant. However, a scholar concluded that the addition of surfactant will lead to decrease the nanofluids electrical conductivity, increase the nanofluids stability and increase nanofluids viscosity [144].

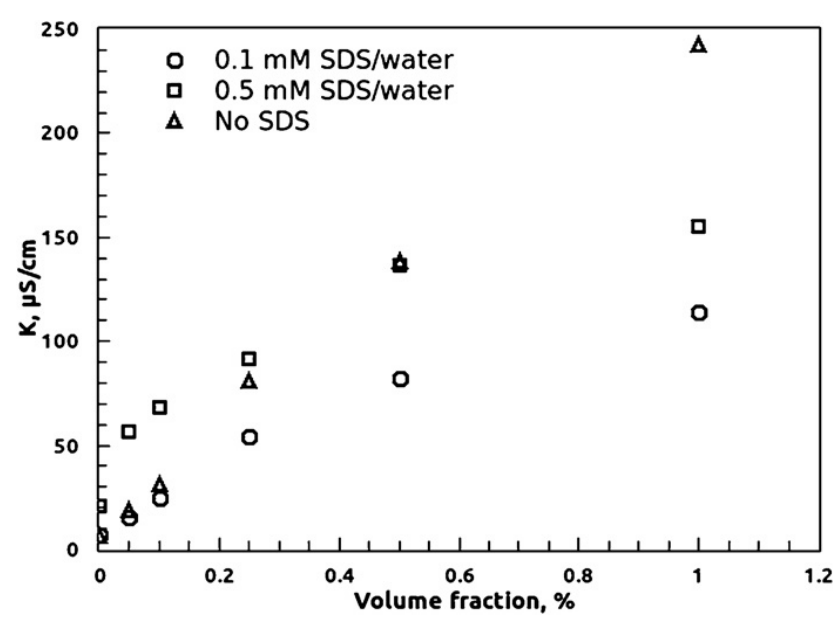

Figure 26: Effect of using SDS surfactant on the $\mathrm{Al}_{2} \mathrm{O}_{3}$ nanofluid electrical conductivity [143] 


\section{CONCLUSION AND RECOMMENDATIONS}

As mention above, the addition of various surfactants can be played an important role in dispersing the nanoparticles into the base fluid and improving the stability of nanofluid and it has significant effects on the other properties of the nanofluids. Table 4 gives a simple summary of effect of surfactants in nanofluids. It should be observed that the technique of surfactant addition cannot be applicable for nanofluid that working in high temperature on account of probable damage of bonding between surfactant and nanoparticle. The purpose of additionally surfactants may hamper heat transfer produce foam when heating. Therefore, surfactants may increase the thermal resistant between the nanoparticle and the base fluids which may lead diminish the enhancement in the thermal conductivity. In order to cover the subject of using surfactants in the nanofluids, it can be recommended the study more effects of surfactant on the electrical and stability properties of the nanofluids.

Table 3: Summary of effect of surfactants in nanofluids.

\begin{tabular}{|c|c|c|}
\hline Nanofluid Properties & $\begin{array}{c}\text { Effect of } \\
\text { Ionic Surfactants }\end{array}$ & $\begin{array}{c}\text { Effect of } \\
\text { Nonionic Surfactants }\end{array}$ \\
\hline Stability and Agglomeration & Decreasing & Decreasing \\
\hline Stability & Increased & Increased \\
\hline Dynamic Viscosity & Increased & Decreased \\
\hline Thermal Conductivity & Increased & Increased \\
\hline pH Values & Increased & Decreased \\
\hline Zeta Potential & Increased & Decreased \\
\hline Surface Tension & Decreased & Decreased \\
\hline Electric Transfer & Increased & Decreased \\
\hline
\end{tabular}

\section{Abbreviations}

\begin{tabular}{|c|c|}
\hline C12E5 & Nonionic pentaoxoethyelenedodecyl ether \\
\hline CDWNTs & carbon double-walled nanotubes \\
\hline CMWNTs & carbon-multiwall nanotubes \\
\hline CNT & carbon nanotubes \\
\hline CsHsCCNa & Sodium benzoate \\
\hline CTAB & cetyltrimethylammonium bromide \\
\hline CTAC & Positively charged cetyltrimethylammoniumchloride \\
\hline DIW & deionized water \\
\hline DTAB & Dodecyl trimethyl ammonium bromide \\
\hline EC & ethylene glycol \\
\hline G & glycerol \\
\hline GA & Gum Arabic \\
\hline HCTAB & Hexadecyltrime thylammonium bromid \\
\hline MWCNT & Sodium dodecylbenzenesulfate \\
\hline NaDDBS & Sodium octylebenzene sulfonate \\
\hline NaOBS & Sodium dodecyl benzene sulfonate \\
\hline NDDBS & Long chain synthetic polymer polyethylene oxide \\
\hline PEO & Poly vinyl pyrroline \\
\hline PVP & Sodium dodecyl sulfate \\
\hline SDS & \\
\hline &
\end{tabular}

\section{REFERENCES}

[1] Choi, S.U.S. 1995. Enhancing thermal conductivity of fluids with nanoparticles, in: D.A. Signer, H.P. Wang (Eds.), Developments Applications of Non-Newtonian Flows, FED-vol. 231/MD, 66, 99-105.

[2] Wen, D., Ding, Y. 2004. Experimental investigation into convective heat transfer of nanofluids at the entrance region under laminar flow conditions, International Journal of Heat and Mass Transfer, 47(24), 51815188.

[3] Wang, Q.X., Mujumdar, SA. 2007. Heat transfer characteristics of nanofluids: a Review", International Journal of Thermal Sciences, 46(1), 119.

[4] Deiss, J.L., Anizan, P., Hadigui, S.El. and Wecker, C. 1996. Steric stability of Ti02 nanoparticles in aqueous dispersions, Colloids and Surfaces A: Physicochemical and Engineering Aspects, 106, 59-62.

[5] Bandyopadhyaya, R., Nativ-Roth, E., Regev, O., and Yerushalmi-Rozen, R. 2002. Stabilization of individual carbon nanotubes in aqueous solutions. Nano Letters, 2(1), 25-28.

[6] Islam, M.F., Rojas, E., Bergey, D.M., Johnson, A.T., and Yodh, A.G. 2003. High weight fraction surfactant solubilization of single-wall carbon nanotubes in water. Nano Letters, 3(2), 269-273.

[7] Leong, K.Y., Hanafi, N.F.M., Sohaimi, R.M., Amer, N.H. 2016. The effect of surfactant on stability and thermal conductivity of Carbon nanotubebased Nano fluids, Thermal science, 20(2), 429-436.
[8] Palabiyik, I., Witharana, S., Musina, Z., Ding, Y. 2013. Stability of glycol nanofluids - the consensus between theory and measurement", Journal of American Science, 9(6).

[9] Gupta, H.K., Agrawal, G.D., Mathur, J. 2012. An overview of Nanofluids: A new media towards green environment, International Journal of Environmental Sciences, 3(1)

[10] Heydarian, A. 2013. Impact of Nano-Particles on Static Performance of Surfactant Foams", Journal of American Science, 9(6).

[11] Drzazga, M., Dzido, G., Lemanowicz, M., Gierczyckiet, A. 2012 Influence of Nonionic Surfactant on Nanofluid Properties",14th European Conference on Mixing Warszawa, 10-13 September 2012.

[12] Drzazga, M., Gierczycki, A., Dzido, G., Lemanowicz, M. 2013 Influence of Nonionic Surfactant Addition on Drag Reduction of Water Based Nanofluid in a Small Diameter Pipe, Chinese Journal of Chemical Engineering, 21(1),104-108.

[13] Morsy, S.M.I. 2014. Role of Surfactants in Nanotechnology and Their Applications, International Journal of current microbiology and Applied Sciences ISSN: 2319-7706, 3(5),237-260.

[14] Faulkner, D., Davison, R.J., Shekarriz, R. 2004. Enhanced heat transfer through the use of nanofluids in forced convection, Proceedings of ASME Heat, Transfer Div., 219.

[15] Wongwises, D., Duangthongsuk, W., Wongwises, S. 2009. Heat transfer enhancement and pressure drop characteristics of TiO2-water nanofluid in a double-tube counter flow heat exchanger, International Journal of Heat and Mass Transfer 52, 2059-2067. 
[16] Arani, A., Amani, G. 2012. Experimental study on the effect of TiO2water nanofluid on heat transfer and pressure drop", Experimental Thermal and Fluid Science, 42, 107-115.

[17] Xuan, Li, Y., Li, Q. 2000. Heat transfer enhancement of nanofluids", International Journal of Heat and Fluid Transfer, 21, 58-64.

[18] Murshed, Leong, K.C., Yang, C. 2005. Enhanced thermal conductivity of TiO2-water based nanofluids", International Journal of Thermal Sciences, 44(4), 367-373.

[19] Zhou, D.W. 2004. Heat transfer enhancement of copper nanofluid with acoustic cavitation", International Journal of Heat and Mass Transfer, 47, 3109-3117.

[20] Ding, Y., Alias, H., Wen, D., and Williams. 2006. Heat transfer of aqueous suspensions of carbon nanotubes (CNT nanofluids)", International Journal of Heat and Mass Transfer, 49, 240-250.

[21] Phuoc, T.X., Massoudi, M., Chen, R.H. 2011. Viscosity and thermal conductivity of nanofluids containing multi-walled carbon nanotubes stabilized by chitosan, International Journal of Thermal Sciences, 50,1218.

[22] Kumaresan, V., Velraj, R. 2012. Experimental investigation of the thermo-physical properties of water-ethylene glycol mixture-based CNT nanofluids, Thermochimica Acta, 545, 180-186.

[23] Harish, S., Ishikawa, K., Einarsson, E., Aikawa, S., Chiashi, S., Shiomi, J., and Maruyama, S. 2012. Enhanced thermal conductivity of ethylene glycol with single-walled carbon nanotube inclusions, International Journal of Heat and Mass Transfer, 55, 3885-3890.

[24] Fadhillahanafi, Leong, K.Y., and Risby, M.S. 2013. Stability and Thermal Conductivity Characteristics of Carbon Nanotube Based Nanofluids, International Journal of Automotive and Mechanical Engineering (IJAME), 8, 1376-1384, July-December 2013.

[25] Lopez, J.A., González, F., Bonilla, F.A., Zambrano, G., Maria, E., and Gómez. 2010. Synthesis and Characterization of Fe304 Magnetic Nanofluid, Revista Latino Americana de Metallurgic Materials, 30(1), 6066.

[26] Chen, L., et al. 2008. Applications of Cationic Gemini Surfactant in Preparing Multi-Walled Carbon Nanotube Contained Nanofluids, Coll. Surf. A., 330(2-3), 176-179.

[27] Thanya, P., Rittidech, S., Pattiya, A., Ding, Y., and Witharana, S. 2011. Application of silver nanofluid containing oleic acid surfactant in a thermosyphon economizer, Nanoscale Research Letters, 6, 315.

[28] Liu, Z.H., and Liao, L. 2010. Forced convective flow and heat transfer characteristics of aqueous drag-reducing fluid with carbon nanotubes added, Int. J. Therm. Sci., 49, 2331-2338.

[29] Lee, J., Kolade, G.B., John, K., Eaton, K.E., and Goodson 2010. Nanofluid Convection in Microtubes", Journal of Heat Transfer, 132, 092401-1.

[30] Lakhawat, G.P., Ugwekar, R.F., Suke, S.G., Vivek, M., and Nanoti. 2017. Effect of nonionic surfactant additives on thperformance of nanofluid in the heat exchanger, Int. J. Nano Dimens., 8(1), 18-30.

[31] Salma, P.E., and Halelfadl, D. 2015. Thermal Conductivity of CNT Water Based Nanofluids Experimental Trends and Modles overview, Journal of Thermal Engineering, 1(2), 381-390.

[32] Ojha, S.R. 2009. Characterization of UL Trafine Al-Cu Powder Particles and Subsequent Dispersion for Heat Transfer Application, Bachelor of Technology Metallurgical \& Materials Engineering.

[33] Sylvio, M. 2012. Nanofluids for heat exchanger improvement: a numerical approach Department de Engenharia, Mechanical Universidad de Aveiro.

[34] Xuan, Y., and Li, Q. 2000. Heat transfer enhancement of nanofluids. International Journal of Heat and Fluid Transfer, 21, 58-64.

[35] Murshed, S.M.S., Leong, K.C., and Yang, C. 2005. Enhanced thermal conductivity of TiO2-Water based nanofluids. International Journal of Thermal Sciences, 44(4), 367-373.
[36] Hwang, Y.J., Ahn, Y.C., Shin, H.S., Lee, C.G., Kim, G.T., Park, H.S., and Lee, J.K. 2005. Investigation on characteristics of thermal conductivity enhancement of nanofluids. Current Applied Physics, 6(6), 1068-1071.

[37] Assael, M.J., Metaxa, I.N., Arvanitidis, J., Christofilos, D., and Lioutas, C. 2005. Thermal conductivity enhancement in aqueous suspensions of carbon multi-walled and double-walled nanotubes in the presence of two different dispersants. International Journal of Thermophysics, 26(3), 647 664.

[38] Yu, W., Xie H. 2012. A Review on nanofluids: Preparation, stability mechanisms, and applications. J. Nanomater. 17: 35873-35878.

[39] Baxi, J. 2008. Tribological Characterization Of Coatings And Nanofluids, Submitted to the Office of Graduate Studies of Texas A\&M University in partial fulfillment of the requirements for the degree of Master of Science.

[40] Yu, W., and Xie, H. 2012. A Review on Nanofluids: Preparation, Stability Mechanisms, and Applications, Journal of Nanomaterials, 1-17.

[41] Jin, H.W., Xianju, L., Qiong, W., Xueyi, Z., Yunjin, L., Liming. 2009. Influence of $\mathrm{pH}$ on the Stability Characteristics of Nanofluids, in: Symposium on Photonics and Optoelectronics, SOPO, 1-4.

[42] Paramashivaiah, B.M., and Rajashekhar, C.R. 2016. Studies on effect of various surfactants on stable dispersion of graphene nano particles in simarouba biodiesel, IOP Conf. Series: Materials Science and Engineering 149. 012083 doi:10.1088/1757-899X/149/1/012083.

[43] Ding, Y., Alias, H., Wen, D., Williams, R.A. 2006. Heat transfer of aqueous suspensions of carbon nanotubes (CNT nanofluids). International Journal of Heat and Mass Transfer, 49, 240-250.

[44] Chen, L., Xie, H., Li, Y., Yu, W. 2008. Applications of cationic gemini surfactant in preparing multi-walled carbon nanotube contained nanofluids. Colloids and Surfaces A: Physicochemical and Engineering Aspects, 330, 176-179.

[45] Kumaresan, V., Velraj, R. 2012. Experimental investigation of the thermo-physical properties of water-ethylene glycol mixture-based CNT nanofluids. Thermochimica Acta, 545, 180-186.

[46] Harish, S., Ishikawa, K., Einarsson, E., Aikawa, S., Chiashi, S., Shiomi, J., Maruyama, S. 2012. Enhanced thermal conductivity of ethylene glycol with single-walled carbon nanotube inclusions. International Journal of Heat and Mass Transfer, 55, 3885-3890.

[47] Alias, H. 2006. Engineered Nanofluids For Heat Transfer Process Intensification, Submitted in accordance with the requirements for the degree of Doctor of Philosophy, The University of Leeds School of Process, Environmental and Materials Engineering.

[48] Allounia, Z.E., Cimpana, M.R., Hol, P.J., Skodvind, T., Gjerdet, N.R. 2009. Agglomeration and sedimentation of TiO2 nanoparticles in cell culture medium, Colloids Surf. B: Biointerf. 68, 83-87.

[49] Thornton, J.D. 1992. Science and Practice of Liquid-Liquid Extraction, 1, 255, 337, Clarendon Press, Oxford.

[50] Sarimeseli, A., Kelbaliyev, G. 2004. Sedimentation of solid particles in turbulent ${ }^{\circ}$ ow in horizontal channels, Powder Technology, 140, 79, 85.

[51] Abade, G.C. and Cunha, F.R. 2007. Computer simulation of particle aggregates during sedimentation, Comput. Methods Appl. Mech. Engrg., $196,4597-4612$.

[52] Chen, L., et al. 2008. Applications of Cationic Gemini Surfactant in Preparing Multi-Walled Carbon Nanotube Contained Nanofluids, Coll. Surf. A., 330, 2-3, 176-179.

[53] Meibodi, M.E., et al. 2010. The Role of Different Parameters on the Stability and Thermal Conductivity of Carbon Nanotube/Water Nanofluids, Int. Commun. Heat Mass Transf., 37(3), 319-323.

[54] Chen, L., Xie, H. 2010. Properties of Carbon Nanotube Nanofluids Stabilized by Cationic Gemini Surfactant, Thermochim Acta, 5061-2, 6266. 
[55] Nasiri, A., et al. 2011. Effect of Dispersion Method on Thermal Conductivity and Stability of Nanofluid, Exp. Therm. Fluid Sci., 35(4), 717723.

[56] Kumaresan, V., Velraj, R. 2012. Experimental Investigation of the Thermo-Physical Properties of Water- Ethylene Glycol Mixture Based CNT Nanofluids, Thermochim Acta, 545, 180-186.

[57] Leong, K.Y., Hanafi, N.F.M., Sohaimi, R.M., Amer, N.H. 2016. The Effect of Surfactant On Stability And Thermal Conductivity Of Carbon Nanotube Based Nanofluids, Leong, K.Y., et al., The Effect of Surfactant on Stability and Thermal, Thermal Science, 20(2), 429-436.

[58] Duangthongsuk, W., Wongwises, S. 2009. Heat transfer enhancement and pressure drop characteristics of TiO2-water nanofluid in a double-tube counter flow heat exchange, International Journal of Heat and Mass Transfer, 52, 2059-2067.

[59] Nasiri, M., Etemad, S.Gh., Bagheri, R. 2011. Experimental heat transfer of nanofluid through an annular duct, Int. Commun. Heat Mass Trans, 38(7), 958-963.

[60] Karthikeyan, N.R., Philip, J., Raj, B. 2008. Effect of clustering on the thermal conductivity of nanofluids. Int. J. Material Chemistry and Phisics, $10,50-55$.

[61] Hwang, Y.J., Lee, J.K., Lee, C.H., Jung, Y.M., Cheong, S.I., Lee, C.G., Ku, B.C., and Jang, S.P. 2007. Stability and thermal conductivity characteristics of nanofluids. Thermochimica Acta, 455(1-2), 70-74.

[62] Ghadimi, A., Saidur, R., Metselaar, H.S.C. 2011. A review of nanofluid stability properties and characterization in stationary conditions. International Journal of Heat and Mass Transfer, 54, 4051-4068.

[63] Kang, S.W. 2009. Experimental Investigation of Nanofluids on Sintered Heat Pipe Thermal Performance, Appl. Therm. Eng., 29, 5-6, 973979.

[64] Wang, X.J., Zhu, D.S., Yang, S. 2009. Investigation of pH and SDBS on enhancement of thermal conductivity in nanofluids, Chem. Phys. Lett. $470(1-3), 107-111$.

[65] Linda, V., Wagner, H.D., Marom, G. 2016. The role of surfactants in dispersion of carbon nanotubes, Advances in Colloid and Interface Science 128-130 (2006) 37-46. IConAMMA-2016 IOP Publishing IOP Conf. Series: Materials Science and Engineering 149, 012083.

[66] Richa, R., Kaushal, R., Tripathi, S.K., Sharma, A.L., Kaur, I., Bharadwaj, L.M. 2008. Comparative study of carbon nanotube dispersion using surfactants, Journal of Colloid and Interface Science, 328, 421-428.

[67] Han, Z. 2008. Nanofluids with Enhanced Thermal Transport Properties. Dissertation for the degree of Doctor of Philosophy, University of Maryland, United States of America.

[68] Fadhillahanafi, N.M., Leong, K.Y. and Risby, M.S. 2013. Stability and Thermal Conductivity Characteristics Of Carbon Nanotube Based Nanofluids, International Journal of Automotive and Mechanical Engineering (IJAME) ISSN: 2229-8649 (Print); ISSN: 2180-1606 (Online); 8, 1376-1384.

[69] Hwang, Y., Lee, J.K., Lee, C.H., Jung, Y.M., Cheong, S.I., Lee, C.G. et al. 2007. Stability and thermal conductivity characteristics of nanofluids, Thermochimica Acta, 455, 70-74.

[70] Timofeeva, E.V. 2010. The Particle Size and Interfacial Effects on Thermo-physical and Heat Transfer Characteristics of Water Based a-SiC Nanofluids. Nanotechnology, 21(21), 215703-13.

[71] Li, L. 2008. An investigation of molecular layering at the liquid-solid interface in nanofluids by molecular dynamics simulation. Physics Letters A, 372(25), 4541-4544.

[72] Ghadimi, A., Metselaar, H. 2013. The influence of surfactant and ultrasonic processing on improvement of stability, thermal conductivity and viscosity of titania nanofluid, Experimental Thermal and Fluid Science, $51,1-9$.

[73] Sahooli, M., Sabbaghi, S., Niassar, M.S. 2012. Preparation of $\mathrm{CuO} /$ Water Nanofluids Using Polyvinylpyrolidone and a Survey on Its
Stability and Thermal Conductivity, Int. J. Nanosci. Nanotechnol, 8(1), $27-$ 34.

[74] Jiang, L., Gao, L. and Sun, J. 2003. Journal of Colloid and Interface Science, 260, 89-94.

[75] Xie, H., Lee, H., Youn, W. and Choi, M. 2003. Journal of Applied Physics, 94, 4967-4971.

[76] Fendler, J.H. 2001. Journal of Chemical Engineering, 18, 1-6.

[77] Lin, X.M., Sorensen, C.M., Klabunde, K.J. 2000. Digestive ripening nanophase segregation and superlattice formation in gold nanocrystal colloids, Journal of Nanoparticle Research, 2, 157-164.

[78] Eastman, J.A., Choi, S.U.S., Li, S., Yu, W., Thompson, L.J. 2001 Anomalously increased effective thermal conductivities of ethylene glycolbased nanofluids containing copper nanoparticles. Appl Phys Lett, 78(6), $718-20$

[79] Lee, J., Mudawar, I. 2007. Assessment of the effectiveness of nanofluids for singlephase and two-phase heat transfer in micro-channels. Int J Heat Mass Transfer, 50(3-4), 452-63.

[80] Choi, C., Yoo, H.S., Oh, J.M. 2008. Preparation and heat transfer properties of nanoparticle-in-transformer oil dispersions as advanced energy-efficient coolants. Curr Appl Phys, 8, 710-2.

[81] Lo, C., Tsung, T., Chen, L. 2006. Ni nano-magnetic fluid prepared by submerged arc nano synthesis system (SANSS). JSME Int J, Ser B: Fluids Therm Eng, 48(4), 750-755.

[82] Chen, L., Xie, H., Li, Y., Yu, W. 2008. Nanofluids containing carbon nanotubes treated by mechanochemical reaction. Thermochim. Acta, 477 , 21-24. [CrossRef].

[83] Hung, Y.H., Wen-Chieh, C. 2012. Chitosan for suspension performance and viscosity of MWCNTs. Int. J. Chem. Eng., 3, 347-353. [CrossRef].

[84] Vaisman, L., Wagner, H.D., and Marom, G. 2006. The Role of Surfactants in Dispersion of Carbon Nanotubes", Advances in Colloid and Interface Science, 128-130, 37-46.

[85] Pantzali, M.N., Kazakis, N.A., Tsolakidis, N., Mouza, A.A., and Tihon, J. 2008. Measuring Transport Properties of Nanofluids, Department of Chemical Engineering, Aristotle University of Thessaloniki, Greece.

[86] Wen, D., Lin, G., Vafaei, S., Zhang, K. 2009. Review of nanofluids for heat transfer applications. Particuology, 7, 141-150.

[87] Henderson, K., Park, Y.G., Liu, L., Jacobi, A.M. 2010. Flow-boiling heat transfer of R-134a-based nanofluids in a horizontal tube. Int J Heat Mass Transf, 53(5-6), 944-951.

[88] Yujin, H., Jae-Keun, L., Jong-Ku, L., Young-Man, J., Seong-ir, C., YoungChull, A., Kim, S.H. 2008. Production and dispersion stability of nanoparticles in nanofluids. Powder Technol, 186, 145-53.

[89] Li, X.F., Zhu, D.S., Wang, X.J., Wang, N., Gao, J.W., Li, H. 2008. Thermal conductivity enhancement dependent $\mathrm{pH}$ and chemical surfactant for CueH2O nanofluids, Thermochim. Acta, 469, 98e103.

[90] Yu, W., Xie, H., Chen, L., Li, Y. 2010. Investigation on the thermal transport properties of ethylene glycol-based nanofluids containing copper nanoparticles, Powder Technol., 197, 218-221.

[91] Yang, L., Chen, X.L., Xu, M.K., Du, K. 2016. Roles of surfactants and particle shape in the enhanced thermal conductivity of TiO2 nanofluids, AIP Advances 6, 095104.

[92] Yang, C. 2005. Enhanced thermal conductivity of TiO2-water based nanofluids Journal of Thermal Sciences, 44, 367-373.

[93] Li, X.F., Zhu, D.S., Wang, X.J., Goa, J.W., Li, H. 2008. Thermal conductivity enhancement depends $\mathrm{pH}$ and Chemical surfactant for $\mathrm{Cu}-$ H2O nanofluids, Thermochim. Acta., 469, 98.

[94] Wang, X., Xu, X., Zhou, L.P., Peng., X.F., Zhang, X.X. 2003. Enhancing the effective thermal Conductivity of liquid with dilute suspensions of Nanoparticles, Symposium on Thermo Physical Properties, Boulder, USA. 
[95] Hwang, Y., Lee, J.K. 2008. Production and dispersion stability of nanoparticles in nanofluids. Powder Technol, 186(2), 145-153.

[96] Murshed, S.M.S., Leong, K.C., Yang, C. 2008. Invesitions of thermal conductivity and viscosity of nanofluids. Int J Therm Sci, 47, 560-568.

[97] Das, S.K., Putra, N., Thiesen, P., Roetzel, W. 2003. Temperature dependence of thermal conductivity enhancement for nanofluids. ASME J Heat Transfer, 125, 567-574.

[98] Beck, M.P., Yuan, Y., Warrier, P., Teja, A.S. 2010. The thermal conductivity of alumina nanofluids in water, ethylene glycol, and ethylene glycol + water mixtures. J Nanopart Res, 12, 1469-1477.

[99] Kole, M., Dey, T.K. 2010. Thermal conductivity and viscosity of Al203 nanofluid based on car engine coolant. J Phys D Appl Phys, 43, 315501.

[100] Estellé, P., Halelfadl, S., Maré, T. 2015. Thermal Conductivity Of Cnt Water Based Nanofluids: Experimental Trends And Models Overview, Journal of Thermal Engineering, Yildiz Technical University Press, Istanbul, Turkey Manuscript Received December 16, 2014; Accepted January 19, 2015, 1(2), 381-390.

[101] Yang, Y., Grulke, E.A., Zhanh, Z.G., Wu, G. 2006. Thermal and rheological properties of carbon nanotube-in-oil dispersions, J. Appl. Phys. 99, 114307.

[102] Lee, J.H., Hwang, K.S., Jang, S.P., Lee, B.H., Kim, J.H., Choi, S.U.S., et al. 2008. Effective viscosities and thermal conductivities of aqueous nanofluids containing low volume concentrations of Al203 nanoparticles". International Journal Heat Mass Transfer, 51(11-12), 2651-6.

[103] Chen, L., Xie, H. 2010. Properties of carbon nanotube nanofluids stabilized by cationic gemini surfactant, Thermochim. Acta 506, $62 \mathrm{e} 66$.

[104] Wusiman, K., Jeong, H., Tulugan, K., Chung, H. 2013. Thermal performance of multiwalled carbon nanotubes (MWCNTs) in aqueous suspensions with surfactants SDBS and SDS, Int. Commun. Heat Mass Transfer, 41, 28e33.

[105] Khairul, M.A., Shah, K., Doroodchi, E., Azizian, R., Moghtaderi, B. 2016. Effects of surfactant on stability and thermo-physical properties of metal oxide nanofluids, International Journal of Heat and Mass Transfer, $98,778-787$.

[106] Wang, X., et al. 2003. Enhancing the Effective Thermal Conductivity of Liquid with Dilute Suspensions of Nanoparticles, Symposium on Thermo Physical Properties, Boulder, Cal., USA.

[107] Xia, G. 2014. Huanming Jiang, Ran Liu, Yuling Zhai, Effects of surfactant on the stability and thermal conductivity of Al203/de-ionized water nanofluids, International Journal of Thermal Sciences, 84, 118e124. [108] Zhou, M.Z., Xia, G.D., Li, J., Chai, L., Zhou, L.J. 2012. Analysis of factors influencing thermal conductivity and viscosity in different kinds of surfactant solutions, Exp. Therm. Fluid Sci., 36, 22e29.

[109] Yang, L., Du, K., Zhang, X. 2012. Influence factors on thermal conductivity of ammoniaewater nanofluids, J. Central South Univ., 19, $1622 \mathrm{e} 1628$.

[110] Suganthi, K.S., Vinodhan, V.L., Rajan, K.S. 2014. Heat transfer performance and transport properties of $\mathrm{ZnO}$ ethylene glycol and $\mathrm{ZnO}-$ ethylene glycol-water nanofluid coolants. Appl. Energy, 135, 548-559.

[111] Ko, G.H., Ho, K., Lee, K., Kim, D.S., Kim, C., Sohn, Y., Choi, M. 2007. An experimental study on the pressure drop of nanofluids containing carbon nanotubes in the horizontal tube, Int. J. Heat Mass Transfer, 50, 4749-4753. [112] Wang, X.J., Zhu, D.S., Yang, S. 2009. Investigation of pH and SDBS on enhancement of thermal conductivity in nanofluids, Chem. Phys. Lett., 470(1-3), 107-111.

[113] Krishnamurthy, S., Bhattacharya, P., Phelan, P.E., Prasher, R.S. 2006. Enhanced mass transport in nanofluids. Nano Letters, 6, 419-423.

[114] Chen, X., Cheng, H. and Ma, J. 1998. A study on the stability and rheological behaviour of concentrated $\mathrm{TiC}>2$ dispersions. Powder Technology, 99, 171-176.
[115] Yang, L. Du, K., Zhang, X.S., Cheng, B. 2011. Preparation and stability of Al203 nanoparticle suspension of ammoniaewater solution, Appl. Therm. Engineering, 31, 3643e3647.

[116] Azizian, R., Doroodchi, E., Moghtaderi, B. 2016. Influence of controlled aggregation on thermal conductivity of nanofluids, J. Heat Transfer, 138(2), 021301.

[117] Wasche, R., Naito, M. 2002. Experimental study on zeta potential and streaming potential of advanced ceramic powders, Powder Technol., 123, $275-281$.

[118] Sahooli, M., Sabbaghi, S., Saboori, R. 2012. Journal Materials Letters, $81,169-172$.

[119] Lu, G., Duan, Y.Y., Wang, X.D. 2014. Surface tension, viscosity and rheology of water-based nanofluids: a microscopic interpretation on the molecular level, J Nanopart. Res, 16(9), 1-11.

[120] Tanvir, S., Qiao, L. 2012. Surface tension of nanofluid-type fuels containing suspended nanomaterials., Nanoscale res.lett., 7, 1.

[121] Chinnam, J., Das, D.K., Vajjha, R.S., Satti, J.R. 2015. Measurements of the surface tension of nanofluids and development of a new correlation. Int. J. of Thermal Sciences, 98, 68-80.

[122] Khaleduzzaman, S.S., Mahbubul, I.M., Shahrul, I.M., Saidur, R. 2013. Effect of particle concentration, temperature and surfactant on surface tension of nanofluids. Int. Comm. in Heat and Mass Transfer, 49, 110-114.

[123] Vafaei, S., Wen, D., Borca-Tasciuc, T. 2011. Nanofluid surface wettability through asymptotic contact angle. Langmuir, 27, 2211-2218.

[124] Harikrishnan, A.R., Dhar, P., Agnihotri, P.K., Gedupudi, S., Das, S.K. 2001. Effects of interplay of nanoparticles, surfactants and base fluid on the interfacial tension of nanocolloids, Colloids and Surfaces A: Physicochemical and Engineering Aspects, 178, 1-40.

[125] Kumar, R., Milanova, D. 2009. Effect of surface tension on nanotube nanofluids. Appl. Physical Letter 94, 073107.

[126] Golubovic, M.N., Madhawa Hettiarachchi, H.D., Worek, W.M., Minkowycz, W.J. 2009. Nanofluids and critical heat flux, experimental and analytical study. Appl. Therm. Eng., 29, 1281-1288.

[127] Bresme, F., Faraudo, J. 2007. Particles as surfactants - similarities and differences. JournalPhysics Condens. Matter, 19, 375110.

[128] Das, S.K., Putra, N., Roetzel, W. 2003. Int. J. Heat Mass Transfer, 46, 851.

[129] Khaleduzzaman, S.S., Mahbubul, I.M., Shahrul, I.M. Saidur, R. 2013. Effect of particle concentration, temperature and surfactant on surface tension of nanofluids, International Communications in Heat and Mass Transfer, 49, 110-114.

[130] Kumar, R., Milanova, D. 2009. Effect of surface tension on nanotube nanofluids, Appl. Phys. Lett., 94(7), 073107.

[131] Chen, R.H., Phuoc, T.X., Martello, D. 2011. Surface tension of evaporating nanofluid droplets, International Journal Heat Mass Transf., 54(11-12), 2459-2466.

[132] Vafaei, S., Purkayastha, A., Jain, A., Ramanath, G., Borca-Tasciuc, T. 2009. The effect of nanoparticles on the liquid-gas surface tension of Bi2Te3 nanofluids, Nanotechnology, 20(18), 185702.

[133] Kathiravan, R., Kumar, R., Gupta, A. 2009. Characterization and pool boiling heat transfer studies of nanofluids. J Heat Transf, 131, 1-8.

[134] Shoghl, S.N., Bahrami, M. 2013. Experimental investigation on pool boiling heat transfer of $\mathrm{ZnO}$, and $\mathrm{CuO}$ water-based nanofluids and effect of surfactant on heat transfer coefficient. Int. Commun. Heat Mass Transf., 45, 122-129.

[135] Albadr, J., Tayal, S., Alasadi, M. 2013. Heat transfer through heat exchanger using Al203 nanofluid at different concentrations. Case Studies Therm. Eng., 1, 38-44.

[136] Malvandi, A., Ganji, D.D. 2014. Brownian motion and thermophoresis effects on slip flow of alumina/water nanofluid inside a 
circular microchannel in the presence of a magnetic field. Int. J. Thermal Science, 84, 196-206.

[137] Hwang, Y., Park, H., Lee, J., Jung, W. 2006. Thermal conductivity and lubrication characteristics of nanofluids, Curr. Appl. Phys., 1, 67-71.

[138] Wu, W.T., Yang, Y.M., Maa, J.R. 1995. Enhancement of nucleate boiling heat transfer and depression of surface tension by surfactant additives. J. Heat Transfer, 117, 526-529.

[139] Wang, X.J., Zhu, D.S., Yang, S. 2009. Investigation of pH and SDBS on enhancement of thermal conductivity in nanofluids, Chem. Phys. Lett., 470(1-3), 107- 111.

[140] Peng, H., Ding, G., Hu, H. 2011. Effect of surfactant additives on nucleate pool boiling heat transfer of refrigerant-based nanofluid, Exp. Therm. Fluid Sci, 35, 960-970.
[141] Botha, S.S. 2007. Synthesis And Characterization of Nanofluids For Cooling Applications, A Ph.D. Thesis, South African Institute For Advanced Materials Chemistry, Faculty of Natural Sciences, University of The Western Cape.

[142] Wen, D., Ding, Y. 2004a. Effective thermal conductivity of aqueous suspensions of carbon nanotubes (Nanofluids). International Journal of Thermophysics and Heat Transfer, 18(4), 481-485.

[143] Shogh, S.N., Jamali, J., Moraveji, M.K. 2016. Electrical conductivity, viscosity, and density of different nanofluids: An experimental study, Experimental Thermal and Fluid Science, 74, 339-346.

[144] Kalpana, K.G., Manoja, S.V., Singha, P.K., Pradeep, T., Dasa, S.K. 2013. Electrical conductivity of ceramic and metallic nanofluids, Colloids and Surfaces A: Physicochem. Eng. Aspects, 417, 39- 46. 